\title{
THE LOCK-IN EFFECT AND THE CORPORATE PAYOUT PUZZLE
}

\author{
Chris Mitchell
}

December 2019

The Institute of Social and Economic Research Osaka University 6-1 Mihogaoka, Ibaraki, Osaka 567-0047, Japan 


\title{
The Lock-In Effect and the Corporate Payout Puzzle
}

\author{
Chris Mitchell*
}

\begin{abstract}
Taxes on capital gains are deferred until realization, whereas dividend taxes are levied upon accrual. This often makes dividends tax-disadvantaged relative to share repurchases, which leads to the payout puzzle: why do firms pay dividends? This paper develops a model of corporate payout policy to demonstrate that tax deferment can also provide a partial solution to the payout puzzle: if shareholders demand repurchase premiums when selling equity back to a firm as compensation for accelerated realizations - then dividend payments can become tax-efficient. This mechanism is appealing because it jointly explains a number of payout regularities without appealing to asymmetric information, incomplete contracting, repurchase constraints, and/or shareholder irrationality.
\end{abstract}

Keywords: Payout Policy, Capital Taxation, Portfolio Choice.

JEL classification: G35, H24, and G50.

${ }^{*}$ Institute of Social and Economic Research, Osaka University, 6-1, Mihogaoka, Ibaraki, Osaka, 567-0047, Japan. Phone: +81-6-6879-8566. E-mail: mitchell@iser.osaka-u.ac.jp. I would like to thank Chris Bennett, Kul Bhatia, James Davies, Mike McCausland, Miguel Molico, Peter Streufert, Tamon Takamura, Yaz Terajima, seminar participants at Osaka University, Sophia University, the University of Ottawa, and Western University for many helpful comments on earlier drafts of this paper. I retain full responsibility for any possible errors. I would also like to acknowledge financial support from JSPS KAKENHI Grant-in-Aid Number $15 \mathrm{H} 05728$. 


\section{Introduction}

Shareholders derive income from dividends and capital gains. Both sources of income have identical value in perfect capital markets without taxation, but their values can diverge when capital income is taxed. In the United States, for instance, dividends and long-term capital gains have a top federal tax rate of $20 \%$, and when you factor-in the ability to postpone taxes on capital gains until realization, the latter's effective tax rate is lower (likely in the range of $11 \%-16 \%$, as discussed below). This tax differential makes dividend payments somewhat of a puzzle, since firms can repurchase equity and generate tax-favored capital gains for their shareholders; a concept enshrined in Fisher Black's 1976 paper "The Dividend Puzzle." The current paper develops a model of corporate payout policy to demonstrate that firms may pay dividends for the very same reason that dividends are currently tax disadvantaged: shareholders often postpone the realization of capital gains for tax purposes. This incentive to delay equity sales - known as the lock-in effect - may require some firms to over-pay when repurchasing equity, which can make tax-disadvantaged dividends optimal. The argument below is built on evidence that both retail and institutional investors often behave in accordance with the lock-in effect, that firms are mindful of shareholder taxes when formulating payout policy, and that stock prices typically appreciate during repurchase programs. Furthermore, the model is able to jointly explain a number of payout regularities without appealing to asymmetric information, repurchase constraints, incomplete contracting, or irrationality.

Payout policy - the choice between dividends and share repurchases - is shown by Miller and Modigliani (1961) to be independent of firm value when capital markets are perfect, investment policy is fixed, investors are rational, and taxes are nil. This follows from the equilibrium condition that wealth-maximizing shareholders are indifferent between receiving $\$ 1 / N$ in cash (a dividend payment split among $N$ shares) and a stream of cash flows with present value $\$ 1 / N$ (via higher ownership concentration following a share repurchase). This irrelevance result fails to hold if one form of payout is tax disadvantaged, however, which is thought to be the case with US dividends owing to: higher statutory tax rates prior to 2003; and the postponement of capital-gains taxes until realization, which lowers the effective tax rate. The second factor produces the lock-in effect mentioned above, which is manifest in the trading behavior of both retail and institutional investors.

Feldstein et al. (1980) appears to be the first study to provide empirical evidence that retail investors time their capital-gains realizations to lower tax burdens. This effect is also identified in Auten and Clotfelter (1982), which further shows that realizations are particularly responsive to the transitory components of capital-gains taxes; a result confirmed by Burman and Randolph (1994) and Auerbach and Siegel (2000), which use instrumental-variables for identification. This evidence is supplemented by Brown and Ryngaert (1992) and Landsman and Shackelford (1995), which show that shareholders typically demand higher share prices when selling equity with larger accrued capital gains. Finally, the evidence in Barber and Odean (2003) and Ivkovic et al. (2005), that investors harvest capital losses in December, is also consistent with tax-motivated realizations. 
This tax conscientiousness among retail investors is consistent with Chey et al.'s (2006) estimate that $90 \%$ of all directly-held stock is placed within taxable accounts, but is not ubiquitous. Some investors consistently make investment mistakes by selling appreciated assets too soon, while failing to realize capital losses in a timely manner; Shefrin and Statman (1985) dub this phenomenon the disposition effect, and both Barber and Odean (2003) and Ivkovic et al. (2005) document its occurrence. The empirical evidence suggests that wealthier and better-educated households are less disposed to making investment errors (i.e., see Ivkovic et al., 2005 and Campbell, 2006).

Retail investors have gradually substituted away from direct equity ownership and towards institutional ownership. This places greater emphasis on the latter's trading behavior when considering lock-in effects. Rather than being a homogeneous group, institutional investors differ greatly regarding their tax exposure: ranging from tax-exempt pension funds and non-profit organizations; to partially-taxed insurance companies - with tax relief for policyholder income; to fully taxable corporations, hedge funds, and mutual funds. Chetty and Saez (2005) estimates that only 15\% of institutional investors are fully nontaxable on a dollar-weighted basis, and since mutual-fund inflows are positively related with a fund's tax efficiency (Bergstresser and Poterba, 2002 and Dimmock et al., 2018), and fund-manager compensation is often tied to asset size, these managers have an incentive to be tax efficient. This indeed seems to be the case: Huddart and Narayanan (2002), Jin (2006), Sialm and Starks (2012), and Dimmock et al. (2018) all provide evidence that investment funds with tax-sensitive clients behave in accordance with the lock-in effect, and Sialm and Starks (2012) and Sialm and Zhang (forthcoming) provide evidence that pre-tax returns are typically not sacrificed by tax-efficient funds. The down-side of tax efficiency is greater capital-gains overhang higher levels of accrued capital gains within a fund, and thus, a higher potential for capital-gains taxes in the future - which is shown by Bergstresser and Poterba (2002) to reduce future inflows. However, since future realizations are timed by the fund itself, the actual impact on shareholder taxes is relatively small according to Sialm and Zhang (forthcoming).

The evidence presented above suggests that shareholders are tax conscious, but do firms share this sentiment when formulating payout policy? A possible "solution" to the payout puzzle is that managers are unconcerned about shareholder taxes, either because shareholders "wash out" dividend taxes with strategies akin to those in Miller and Scholes (1978), or that managers are apathetic towards shareholders due to agency problems. Although both issues are probably relevant, the evidence suggests that taxes do matter for payout. Lie and Lie (1999) appears to be the first study to test for such an effect, and concludes that shareholder taxes influence the decision to use special dividends versus self-tender repurchase offers. Poterba (2004) also finds an effect using seventy-five years of time-series data, and concludes that dividends respond to tax changes with a lag. Chetty and Saez (2005, 2006) and Brown et al. (2007) all exploit the Jobs and Growth Tax Relief and Reconciliation Act of 2003 - which reduced the dividend tax disadvantage - as a natural experiment. All three papers find that dividend payments increased significantly following the reform 
(both statistically and economically), and Brown et al. (2007) concludes that share repurchases also declined. Finally, Moser (2007) finds an effect using panel data over the period 1986-2004 capturing a number of tax-rate changes - and concludes that dividend payments (share repurchases) are more likely to occur when the dividend tax rate is low (high) relative to the capital-gains tax rate. Interestingly, most of these studies also find that payout policy is more responsive to tax-rate changes when institutional ownership is high, especially when executives have limited equity stakes (i.e., higher agency problems as in Jensen and Meckling, 1976).

With this backdrop of shareholder lock-in effects and tax-efficient payout policy, the model's primary mechanism is straight-forward to describe. Firms in the model use per-period profits to pay dividends, repurchase shares, and make capital investments. Managers act in the interest of shareholders and choose investment/payout policy to maximize equity value. Once all positive net-present-value projects are fully funded, management decides what fraction of aggregate payout to distribute as dividends, and what fraction to use repurchasing shares. Both forms of payout are subject to capital-income tax, and dividends are taxed more heavily. Shareholders are heterogeneous regarding their investment horizons and level of accrued capital gains on firm equity, and shareholder wealth maximization is shown to create a wedge between equity's market value and the price demanded by shareholders when selling equity with accrued capital gains and nonzero desired holding periods - compensation for the lock-in effect. This differential - referred to as a the "lock-in premium" herein - is weakly positive and increasing in both capital gains and investment horizons. Firms may therefore be required to pay lock-in premiums when repurchasing equity, which is acceptable provided these premiums remain small, since the alternative is paying a tax-disadvantaged dividend. However, since firms typically repurchase large quantities of equity, especially over multiple years $1^{1}$ the marginal shareholder's lock-in premium can become sufficiently large that paying a tax-disadvantaged dividend becomes optimal. At this point, firms switch to dividends. It is shown that dividend payments are more likely (and likely to be larger) when stock prices have risen, when the average holding period increases, when the variance of capital gains and/or holding periods decrease, as firms mature, when firms have relatively large and stable free cash flow, and when dividend taxes (capital gains taxes) decrease (increase). Furthermore, the model suggests that long-run corporate-capital stocks are largely unaffected by the dividend tax rate - consistent with the so-called "New" view, and inconsistent with the "Traditional" view while they are decreasing in both the corporate-profits tax and the capital-gains tax.

The appeal of this mechanism for explaining dividend payout is twofold. First, it requires no restrictions on share repurchases, shareholder information sets, the completeness of contracts, and/or

\footnotetext{
${ }^{1}$ The announcement size of a typical repurchase program is reported to be $6.6 \%$ in Ikenberry et al. (1995), 6.8\% in Gaspar et al. (2012), 7\% in Stephens and Weisbach (1998), 7.5\% in Chan et al. (2010), and 8\% in Jagannathan et al. (2000); in addition, Stephens and Weisback (1998) report that many firms repurchase more equity than they announce. Furthermore, Skinner (2008) reports that repurchasing firms do so every 2 out of 3 years on average (since 1990). Taken together, the average annual repurchase amount - among repurchasing firms - is probably close to Dittmar and Field's (2015) estimate of $5.7 \%$.
} 
rationality $:^{2}$ the only assumption from Miller and Modigliani (1961) to be relaxed is zero taxes $:^{3}$ This is not meant to question the validity of these restrictions, only to point out that skeptics of their applicability - for a particular firm at a particular time - may find the current model's paucity of qualifying assumptions appealing. In any case, manages hold heterogeneous views on what factors drive payout policy - as documented by Brav et al. (2005) - so any one model of payout policy is unlikely to explain the behavior of all firms. The model's second appealing feature is its ability to jointly explain a number of empirical observations. First of all, the model explains why stock prices appreciate during repurchase programs (Ikenberry et al. 1995). Why prices fail to react when no equity is repurchased subsequent to a repurchase announcement (Stephens and Weisbach 1998). Why firms are more likely to repurchase equity following a reduction in stock prices (Skinner 2008), and when the average holding period among shareholders declines (Gaspar et al. 2012). Why dividend payments are more likely among highly-profitable firms (Fama and French 2001). Why payout policy responds to tax changes in cases when dividends remain tax disadvantaged (Chetty and Saez 2005). Why firms are more likely to initiate payout using a share repurchase (Brav et al. 2005), and often pay dividends as they mature (Grullon and Michaely 2002). And why firms are more likely to distribute stable cash flows using dividends, and distribute unstable cash flows using share repurchases (Jagannathan et al. 2000).

The remainder of this paper is organized as follows. Section 2 discusses the previous literature and how this paper fits within it. Section 3 provides an empirical context for the model by illustrating that dividends are tax disadvantaged in the United States. Section 4 derives the main payout model and presents a number of comparative statics. Section 5 extends this model by endogenizing the shareholder distribution. Section 6 concludes.

\section{Literature}

The theoretical literature on why firms pay tax-disadvantaged dividends is both rich and broad, and can be segmented by the four restrictions mentioned above, i.e., constraints on share repurchases, constraints on information sets, the incompleteness of contracts, and irrationality 4 Starting with the first, King (1977), Auerbach (1979), and Bradford (1981) assume that firms avoid equity

\footnotetext{
${ }^{2}$ As discussed in Section 2, these factors are highlighted in the following studies. 1) Repurchase constraints: King (1977), Auerbach (1979), Bradford (1981), and Grullon and Michaely (2002). 2) Asymmetric information: Bhattacharya (1979), John and Williams (1985), Ofer and Thakor (1987), Brennan and Thakor (1990), Bernheim (1991), and Allen et al. (2000). 3) Incomplete contracting: Easterbrook (1984), Jensen (1986), Allen et al. (2000), and Morck and Yeung (2005). And 4) Irrationality: Shefrin and Statman (1984), Bagwell and Shoven (1989), and Baker and Wurgler (2004).

${ }^{3}$ Some papers (e.g., Bagwell and Shoven 1989) note that firms may tailor payout policy to certain tax clienteles: firms that cater to shareholders with a dividend-tax advantage (e.g., certain non-pass-through corporations) will pay dividends, while those catering to shareholders with a dividend-tax disadvantage (e.g., hedge funds and mutual funds) will repurchase shares. However, since most of the market's capitalization is concentrated in firms that pay dividends and repurchase shares (Skinner 2008), shareholders that gravitate towards either dividend-only firms or repurchase-only firms will be grossly under diversified.

${ }^{4}$ Dividends may also be paid due to transactions costs of buying and selling equity, where the latter affects shareholders that consume out of realized capital gains.
} 
buybacks, in part, due to Section 302 of the Internal Revenue Code (implicit in King, 1977 and Bradford, 1981), whereby share repurchases that resemble dividend payments (proportional repurchases) are taxed as such ${ }^{5}$ In addition, Grullon and Michaely (2002) argues that some firms were concerned that repurchasing equity would have triggered antimanipulative provisions of the Securities and Exchange Act prior to the adoption of rule 10b-18 in 1982, which provides guidelines for repurchasing equity safely ${ }_{6}^{6}$ The current paper places no restrictions on payout policy beyond the standard non-negative dividend constraint.

Regarding the second restriction, Bhattacharya (1979) and Ofer and Thakor (1987) argue that dividend payments signal firm value by exposing firms to costly external finance: dividend taxes are necessary for Bhattacharya's (1979) separating equilibria, while they affect the payout mix in Ofer and Thakor (1987). John and Williams (1985) and Bernheim (1991) also require dividend taxes to generate separating equilibira: dividend payments reduce equity dilution in John and Williams (1985), while they fine-tune payout taxes in Bernheim (1991). In addition to addressing information problems between managers and shareholders, Brennan and Thakor (1990) and Allen et al. (2000) show that dividends can address information problems among shareholders: dividend payments forestall the transfer of wealth from uninformed to informed shareholders during repurchase programs in Brennan and Thakor (1990), while they attract informed shareholders in Allen et al. (2000). The current paper assumes that all market participants have the same information.

Regarding the third restriction, Jensen (1986) seems to be the quintessential argument in favor of using dividend payments to extract free cash flow, although it does champion interest payments for this purpose. Morck and Yeung (2005) argue that bankruptcy concerns make dividend payments the superior option. Allen et al. (2000) and Morck and Yeung (2005) argue that dividends attract large institutional investors that reduce collective-action problems (Morck and Yeung 2005) and increase monitoring effort. Easterbrook (1984) also highlights monitoring, but focuses on external monitoring brought about by high dividend payments leading to external finance more often (as in Bhattacharya, 1979 and Ofer and Thakor, 1987). Easterbrook (1984) also notes that dividends may offset managerial risk-aversion by increasing leverage, and therefore, equity value. The current paper assumes that managers act in the interest of shareholders, and only invest in positive net-present-value projects.

Finally, there are two sets of explanations pertaining to irrationality: irrational managers and irrational shareholders. Regarding the first, Bagwell and Shoven (1989) propose that managers have gradually learned to appreciate the net benefit of share repurchases over time, and that Nixon's price and wage ceilings of the 1970s - which led to "voluntary" dividend controls according to Ofer and Thakor (1987) - initiated their learning-by-doing process. When this argument is coupled

\footnotetext{
${ }^{5}$ See Brennan and Thakor (1990) for a description of Section 302's guidelines.

${ }^{6}$ See Jagannathan et al. (2000) for details of rule 10b-18.
} 
with Lintner's (1956) dividend-stickiness model, the payment of current dividends is understandable.7 With regard to shareholder irrationality, Shefrin and Statman (1984) argues that firms pay dividends because shareholders suffer from regret aversion and/or self-control issues; and since preferences are guided by prospect theory (rather than expected-utility theory), mental-accounting creates a value for dividends. In addition, Baker and Wurgler (2004) argues that shareholders have time-varying preferences for dividend-paying firms (or conversely, growth-oriented firms), and that firms cater to these inexplicable preferences by initiating, continuing, or omitting dividend payments. The current paper assumes that both managers and shareholders are perfectly rational, and that shareholders are expected-wealth maximizes.

The current study is also related to theoretical work on share repurchases and equity-supply curves. Two relevant papers are Stulz (1988) and Bagwell (1991), which study upward-sloping equity-supply curves in the context of corporate takeovers, and note that lock-in effects may contribute to their positive gradients. Stulz (1988) argues that share repurchases are useful for increasing takeover-bid premiums, but reduce success probability, while Bagwell (1991) highlights their usefulness as a takeover defense, since repurchasing equity increases acquisition costs. Evidence for upward-sloping equity-supply curves, in the context of Dutch repurchase auctions, is provided by Bagwell (1992). The current paper differs from Stulz (1988) and Bagwell (1991) in a number of important ways. First, it deals with dividend policy (a regularly-occurring consideration for most firms) and not takeover strategy (a comparatively less-frequent consideration). Second, payout policy in the current model involves a trade-off between taxes on dividends and capital gains, while in Stulz (1988) and Bagwell (1991) it involves wealth transfers between target-firm shareholders and acquiring-firm shareholders. Third, a greater emphasis is placed on characterizing the mapping between shareholder characteristics and lock-in premiums in the current study, which is important for understanding its static properties, its comparative statics, and its dynamic properties. Furthermore, the current model provides a more holistic analysis of the firm's investment/payout policy, and how dividends and share repurchases evolve over time.

In addition to Stulz (1988) and Bagwell (1991), Barclay and Smith (1988), Chowdhry and Nanda (1994), and Huang and Thakor (2013) all highlight the positive relationship between share repurchases and stock prices. This relationship is attributable to higher bid-ask spreads in Barclay and Smith (1988), the information content of share repurchases in Chowdhry and Nanda (1994), and the reduction in shareholder-manager disagreement in Huang and Thakor (2013). The current paper differs from these studies for reasons similar to those above: the current paper assumes complete information and perfect rationality.

\footnotetext{
${ }^{7}$ Brav et al. (2005) also documents that some managers pay dividends because of inertia; wishing they had never started.
} 


\section{Empirical Payout}

This section provides an empirical context for the model by illustrating the US payout puzzle over the period 1980-2017. This is done by establishing both the prevalence of dividend payments over this period and their tax disadvantage relative to share repurchases.

Since capital gains are taxed upon realization, the effective tax rate on accrued capital gains (denoted by $\tau_{e}$ ) is necessarily lower than the statutory tax rate on realized capital gains (denoted by $\tau_{g}$ ). To see this, suppose that an asset appreciates by $\$ 1$ today and is liquidated in $T$ periods. The tax liability thus created - due in $T$ periods - can be satisfied by investing $\tau_{g} /\left(1+r_{f}\right)^{T}$ in a risk-free security with after-tax interest rate $r_{f}$. As such, $\tau_{e}=\tau_{g} /\left(1+r_{f}\right)^{T} \leq \tau_{g}$ is the effective tax rate, which is decreasing in $r_{f}$ and $\left.T\right]^{8}$ This raises the question: what is the holding period and interest-tax rate for a typical "marginal investor" who sets equity prices? This question is indirectly addressed by Protopapadakis (1983) and Chay et al. (2006), which suggest that $\tau_{e} / \tau_{g}$ is approximately 0.55 to 0.8 for US equities $9^{9}$

Since share repurchases generate accrued capital gains for most investors, it is standard to apply the effective tax rate $\tau_{e}$ when valuing this form of income 10 Alternatively, since dividends are taxed upon accrual, no adjustment is needed for the dividend tax rate (denoted by $\tau_{d}$ ). If we characterize the "dividend tax preference parameter" from Poterba (2004) as:

$$
\theta_{t}=\frac{\left(1-\tau_{d, t}\right)}{\left(1-\tau_{e, t}\right)}
$$

where $\tau_{d, t}$ is the top federal tax rate on dividend income in year $t$, and $\tau_{e, t}$ is $80 \%$ of the top federal tax rate on long-term capital gains in year $t$ (the top federal rates are used because capital income mostly accrues to high-income individuals), then Table 1 illustrates that dividends were likely to be tax-disadvantaged in every year between 1980-2017, since the after-tax income from a $\$ 1$ gross dividend payment was approximately $\theta_{t}<1$ of the after-tax income from a $\$ 1$ share repurchase in year $t$.

From Table 1 it would appear that US corporations should have avoided dividend payments altogether between 1980-2017. This, of course, was not the case. Despite being tax disadvantaged, dividends were a significant component of corporate payout in every year. This is illustrated by Figures 1 and 2, which plot aggregate dividend payments and share repurchases (in 2017 dollars), and the percentage of firms paying each, respectively, over the period 1980-2017 by Compustat-listed

\footnotetext{
${ }^{8}$ This explanation is similar to that in Constantinides (1983), and is well articulated by King (1977, p. 59): "Deferral is equivalent to an interest-free loan from the revenue authorities to the taxpayer of an amount equal to the tax liability on the accrued gain, and hence is also equivalent to a reduction in the effective rate of tax."

${ }^{9}$ Poterba et al. (1987) suggests a significantly lower rate of 0.25 , which is partially supported by Ivkovic et al. (2005).

${ }^{10}$ Share repurchases also generate realized capital gains for selling shareholders; an important feature of the analysis below.
} 
Table 1. Top Federal Tax Rate on Dividends and Long-Term Capital Gains (US: 1980-2017)

\begin{tabular}{|c|c|c|c|c|c|c|c|c|c|}
\hline \multirow[b]{2}{*}{ Year } & \multirow{2}{*}{$\begin{array}{l}\text { Div. } \\
\tau_{d, t} \\
(1)\end{array}$} & \multicolumn{2}{|c|}{ Cap. Gains } & \multirow[b]{2}{*}{$\begin{array}{c}\theta_{\mathrm{t}} \\
(4)\end{array}$} & \multirow[b]{2}{*}{ Year } & \multirow{2}{*}{$\begin{array}{l}\underline{\text { Div. }} \\
\tau_{d, t} \\
(5)\end{array}$} & \multicolumn{2}{|c|}{ Cap. Gains } & \multirow[b]{2}{*}{$\begin{array}{r}\theta_{\mathrm{t}} \\
(8)\end{array}$} \\
\hline & & $\begin{array}{c}\text { Realized } \\
\tau_{g, t} \\
(2)\end{array}$ & $\begin{array}{c}\text { Accrued } \\
\tau_{e, t} \\
(3)\end{array}$ & & & & $\begin{array}{c}\text { Realized } \\
\tau_{g, t} \\
(6)\end{array}$ & $\begin{array}{c}\text { Accrued } \\
\tau_{e, t} \\
(7)\end{array}$ & \\
\hline 1980 & $70.0 \%$ & $28.0 \%$ & $22.4 \%$ & 0.39 & 1999 & $39.6 \%$ & $20.0 \%$ & $16.0 \%$ & 0.72 \\
\hline 1981 & $69.1 \%$ & $20.0 \%$ & $16.0 \%$ & 0.37 & 2000 & $39.6 \%$ & $20.0 \%$ & $16.0 \%$ & 0.72 \\
\hline 1982 & $50.0 \%$ & $20.0 \%$ & $16.0 \%$ & 0.60 & 2001 & $39.1 \%$ & $20.0 \%$ & $16.0 \%$ & 0.73 \\
\hline 1983 & $50.0 \%$ & $20.0 \%$ & $16.0 \%$ & 0.60 & 2002 & $38.6 \%$ & $20.0 \%$ & $16.0 \%$ & 0.73 \\
\hline 1984 & $50.0 \%$ & $20.0 \%$ & $16.0 \%$ & 0.60 & 2003 & $15.0 \%$ & $15.0 \%$ & $12.0 \%$ & 0.97 \\
\hline 1985 & $50.0 \%$ & $20.0 \%$ & $16.0 \%$ & 0.60 & 2004 & $15.0 \%$ & $15.0 \%$ & $12.0 \%$ & 0.97 \\
\hline 1986 & $50.0 \%$ & $20.0 \%$ & $16.0 \%$ & 0.60 & 2005 & $15.0 \%$ & $15.0 \%$ & $12.0 \%$ & 0.97 \\
\hline 1987 & $38.5 \%$ & $28.0 \%$ & $22.4 \%$ & 0.79 & 2006 & $15.0 \%$ & $15.0 \%$ & $12.0 \%$ & 0.97 \\
\hline 1988 & $28.0 \%$ & $28.0 \%$ & $22.4 \%$ & 0.93 & 2007 & $15.0 \%$ & $15.0 \%$ & $12.0 \%$ & 0.97 \\
\hline 1989 & $28.0 \%$ & $28.0 \%$ & $22.4 \%$ & 0.93 & 2008 & $15.0 \%$ & $15.0 \%$ & $12.0 \%$ & 0.97 \\
\hline 1990 & $28.0 \%$ & $28.0 \%$ & $22.4 \%$ & 0.93 & 2009 & $15.0 \%$ & $15.0 \%$ & $12.0 \%$ & 0.97 \\
\hline 1991 & $31.0 \%$ & $28.0 \%$ & $22.4 \%$ & 0.89 & 2010 & $15.0 \%$ & $15.0 \%$ & $12.0 \%$ & 0.97 \\
\hline 1992 & $31.0 \%$ & $28.0 \%$ & $22.4 \%$ & 0.89 & 2011 & $15.0 \%$ & $15.0 \%$ & $12.0 \%$ & 0.97 \\
\hline 1993 & $39.6 \%$ & $28.0 \%$ & $22.4 \%$ & 0.78 & 2012 & $15.0 \%$ & $15.0 \%$ & $12.0 \%$ & 0.97 \\
\hline 1994 & $39.6 \%$ & $28.0 \%$ & $22.4 \%$ & 0.78 & 2013 & $20.0 \%$ & $20.0 \%$ & $16.0 \%$ & 0.95 \\
\hline 1995 & $39.6 \%$ & $28.0 \%$ & $22.4 \%$ & 0.78 & 2014 & $20.0 \%$ & $20.0 \%$ & $16.0 \%$ & 0.95 \\
\hline 1996 & $39.6 \%$ & $28.0 \%$ & $22.4 \%$ & 0.78 & 2015 & $20.0 \%$ & $20.0 \%$ & $16.0 \%$ & 0.95 \\
\hline 1997 & $39.6 \%$ & $20.0 \%$ & $16.0 \%$ & 0.72 & 2016 & $20.0 \%$ & $20.0 \%$ & $16.0 \%$ & 0.95 \\
\hline 1998 & $39.6 \%$ & $20.0 \%$ & $16.0 \%$ & 0.72 & 2017 & $20.0 \%$ & $20.0 \%$ & $16.0 \%$ & 0.95 \\
\hline
\end{tabular}

Columns 1 and 5 report the top federal tax rate on dividends in the United States from 1980 to 2017. Columns 2 and 6 report the top federal tax rate on long-term capital gains (the federal tax rate on long-term capital gains in 1997 was $28 \%$ prior to May 7 th, and $20 \%$ afterwards), while columns 3 and 7 report estimates of the effective tax rate on accrued capital gains using an effective-to-statutory ratio of 0.8 . Finally, columns 4 and 8 report the dividend tax preference parameter (Equation 1 for each year. The tax preference parameter is below unity in all 38 years, implying that dividends were tax-disadvantaged relative to share repurchases over the entire period.

firms headquartered in the US ${ }^{11}$ As illustrated by Figure 1, dividends were the largest component of corporate payout until 1997, and although share repurchases assumed this position afterwards - except in 2009 - aggregate dividends remained sizable and grew in most years (average growth rate of 4.8\% per year from 1997-2017). Furthermore, as illustrated by Figure 2, more firms paid dividends than repurchased shares for most of the period 1980-1994. However, the percentage of dividend-paying firms has declined substantially over time: from $58 \%$ in 1980 to $15.6 \%$ in 2001 (Fama and French, 2001 attribute much of this to firm-composition effects). This percentage has picked up recently, however, reaching $29 \%$ by 2017.

Although share repurchases have become more prominent in recent years, dividends have not

\footnotetext{
${ }^{11}$ In keeping with the previous literature, both utilities and financial institutions - which typically pay high dividends - are excluded from the sample due to their unique regulatory environments (Standard Industrial Classification codes 4900-4949 and 6000-6999, respectively). See Appendix A for a description of each payout variable.
} 
Figure 1. Aggregate Dividends and Share Repurchases (US: 1980-2017)

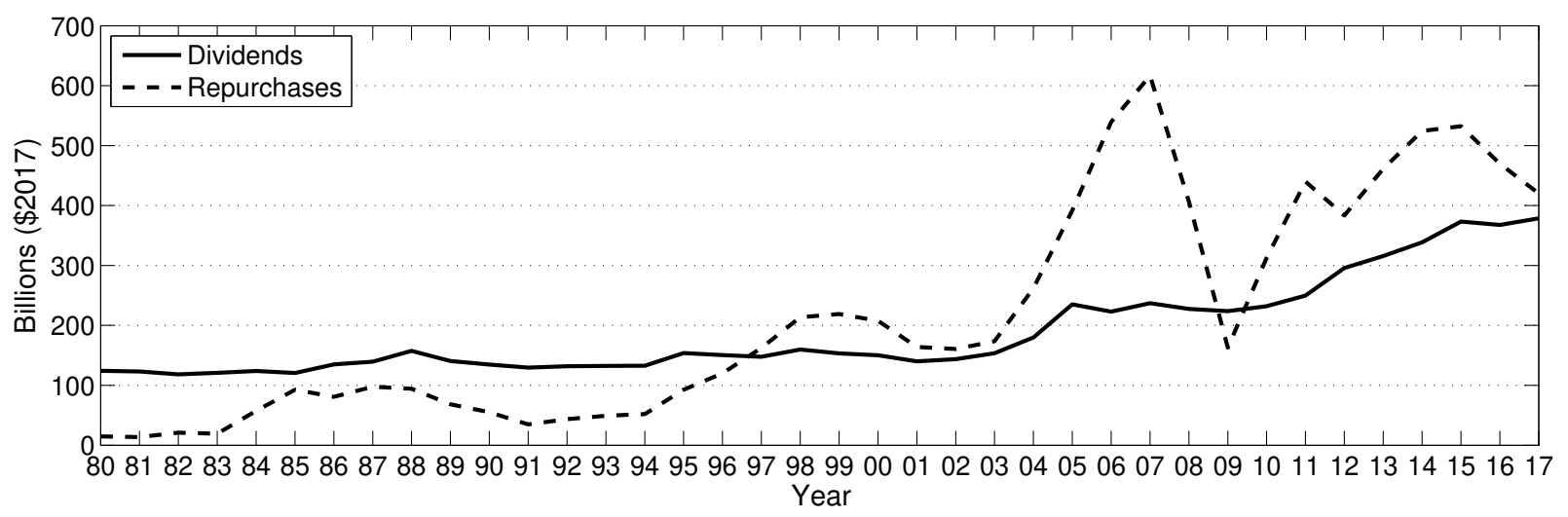

This figure plots the aggregate level of real dividends (solid line) and share repurchases (dashed line) by Compustat-listed firms headquartered in the United States (excluding utilities and financial institutions), over the period 1980-2017 (in 2017 dollars).

Figure 2. Fraction of Firms Paying Dividends and Repurchasing Equity (US: 1980-2017)

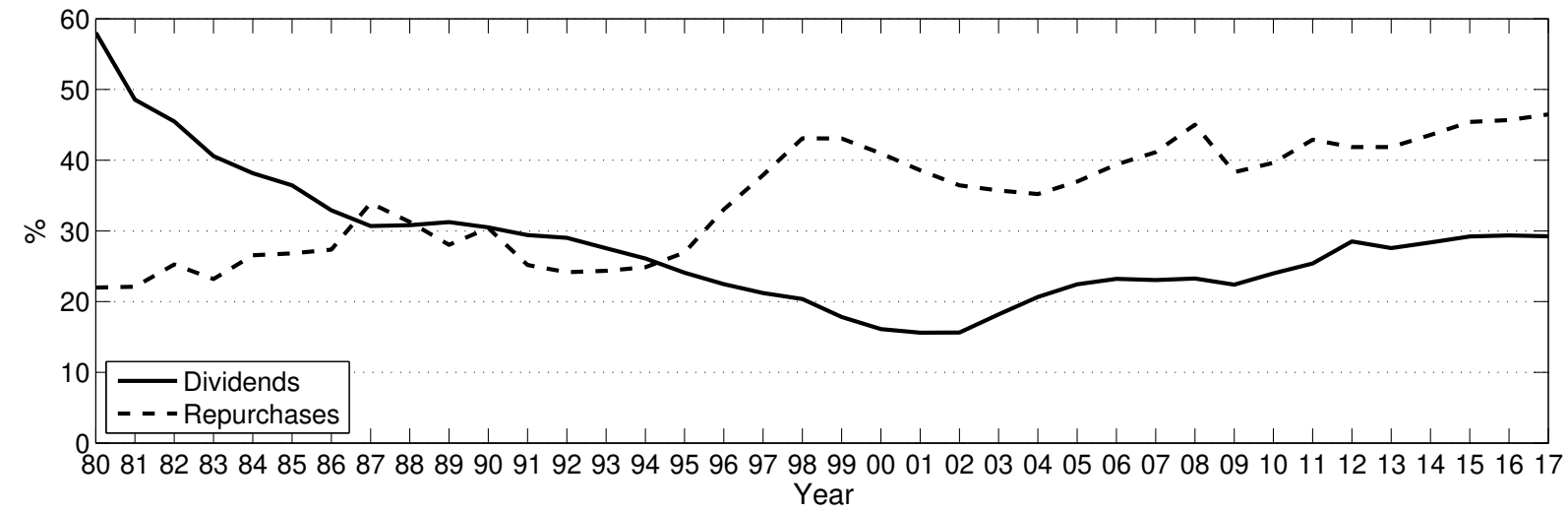

This figure plots the fraction of Compustat-listed firms headquartered in the United States (excluding utilities and financial institutions) that paid dividends (solid line) and repurchased equity (dashed line), in each year between 1980-2017.

disappeared, and continue to be a significant component of corporate payout. The model developed below provides an explanation for this.

\section{Model}

This section develops the payout model. It begins by characterizing firms and shareholders, then it derives the model's steady-state equilibria, which is followed by a number of comparative statics that provide empirical support for the model.

\subsection{Firms}

Firms in the model are all-equity financed; this allows us to abstract from issues related to capital structure, and to focus on payout policy. The stock market discounts income generated by the 
firm, net of all applicable taxes, at the constant rate $1 /(1+\rho)$ per-period, where $\rho>0$. Consistent with shareholder rationality, the stock market values after-tax income from dividends and share repurchases identically (the latter takes the form of capital gains). There are two levels of taxation: firms pay corporate-profits tax at the rate $\tau_{c}$; while shareholders pay income tax at the rate $\tau_{d}$ on dividends, and $\tau_{g}$ on realized capital gains. These rates are constant across firms, shareholders, and time. There is no uncertainty in the model, all information is symmetric, and firms live forever.

Firms begin each period $t$ with a given level of non-depreciating capital $K_{t}$ carried over from the previous period. This is used to generate end-of-period profits according to the function $\pi(K)$, where $\pi^{\prime}(K)>0$ and $\pi^{\prime \prime}(K)<0$. When gross profits are generated, firms simultaneously pay corporate-profits tax, issue dividends, repurchase equity, and make capital investments, in that order. Firms can also issue equity (negative share repurchases) and divest capital (negative investment), but they cannot pay negative dividends. Managers are assumed to act in the interest of shareholders by maximizing firm value $(V)$. This is accomplished by selecting a feasible sequence of dividend payments, share repurchases, and investment levels subject to the firm's beginning-ofperiod capital stock.

Given these assumptions, a gross dividend payment $D_{t}$ produces end-of-period net income $\left(1-\tau_{d}\right) D_{t}$, while the net income from an accrued capital gain $\Delta V_{t}$ is typically higher than $\left(1-\tau_{g}\right) \Delta V_{t}$, since, as discussed in Section 3 , the effective tax rate on $\Delta V_{t}$ is typically lower than $\tau_{g}$. If we continue to denote the market's effective tax rate on accrued capital gains by $\tau_{e}$, then these gains have a net notional value of $\left(1-\tau_{e}\right) \Delta V_{t}$ at the end of period $t$. Taken together, the firm's market value at the beginning of period $t$ is:

$$
V_{t}=\frac{\left(1-\tau_{d}\right) D_{t}}{(1+\rho)}+\frac{\left(1-\tau_{e}\right) \Delta V_{t}}{(1+\rho)}+\frac{V_{t}}{(1+\rho)} .
$$

Capital gains can be generated in two different ways within the model: capital investment and share repurchases. The former method results in higher continuation values, i.e., $V_{t+1}>V_{t}$, while the latter increases ownership concentration, i.e., $V_{t+1} /\left(1-\alpha_{t}\right)>V_{t+1}$, where $\alpha_{t}>0$ is the fraction of equity repurchased in period $t$, which equals:

$$
\alpha_{t}=\frac{R_{t}}{V_{t+1}+R_{t}}
$$

where $R_{t}$ is the market value of repurchased equity 12 Therefore, capital gains at the end of period $t$ are:

\footnotetext{
${ }^{12}$ This equation can be derived as follows. Denote by $N_{t}$ the number of perfectly-divisible outstanding shares at the beginning of period $t$. Then $R_{t}=\left(N_{t} \alpha_{t}\right)\left(V_{t+1} / N_{t}\left(1-\alpha_{t}\right)\right)$, i.e., the firm repurchases $N_{t} \alpha_{t}$ of its shares during the repurchase program, and each of these shares is worth $V_{t+1} / N_{t}\left(1-\alpha_{t}\right)$, where this valuation follows from the firm's continuation value of $V_{t+1}$ being split equally among the remaining $N_{t}\left(1-\alpha_{t}\right)$ shares. Canceling the $N_{t}$ terms, and rearranging this expression, produces Equation 3 .
} 


$$
\Delta V_{t}=V_{t+1} /\left(1-\frac{R_{t}}{V_{t+1}+R_{t}}\right)-V_{t}
$$

which simplifies to:

$$
\Delta V_{t}=V_{t+1}+R_{t}-V_{t}
$$

Substituting Equation 4 into Equation 2 produces the following firm value:

$$
V_{t}=\frac{\left(1-\tau_{d}\right) D_{t}}{(1+\rho)}+\frac{\left(1-\tau_{e}\right)\left(V_{t+1}+R_{t}-V_{t}\right)}{(1+\rho)}+\frac{V_{t}}{(1+\rho)}
$$

and solving for $V_{t}$ produces:

$$
V_{t}=\left[1+\frac{\rho}{\left(1-\tau_{e}\right)}\right]^{-1}\left(\frac{\left(1-\tau_{d}\right)}{\left(1-\tau_{e}\right)} D_{t}+R_{t}+V_{t+1}\right) .
$$

This is a common firm-value equation, but deserves a brief explanation. The end-of-period market value of a gross dividend payment $D_{t}$ is equal to the after-tax cash receipt $\left(1-\tau_{d}\right) D_{t}$, plus the subsequent capital-loss offset that is created once the stock becomes ex-dividend. When both of these are fully capitalized into the stock's market price, the value of a marginal dividend - just prior to its payment - is equal to $\left(1-\tau_{d}\right) /\left(1-\tau_{e}\right)$. Conversely, share repurchases - just prior to the repurchase program - have no tax implications for marginal investors, as the program's full value is already capitalized into the stock's price. This implies that both $R_{t}$ and $V_{t+1}$ have a unit coefficient at the end of period $t$. However, the story is different when capital gains are expected to materialize in the future. Here, marginal investors rightly anticipate the future tax liability on these gains, and the discount factor is adjusted (reduced) accordingly. This is seen from the square-bracketed term of Equation 5, which has $\rho$ inflated by the factor $1 /\left(1-\tau_{e}\right){ }^{13}$ This modified discount factor is applied to end-of-period dividends and share repurchases equally, as both constitute a capital gain when viewed from the beginning of a period (i.e., they both increase equity's market value).

Moving on, the firm's market value from Equation 5 can be transformed into the following infinite sequence of payout:

$$
V_{t}=\sum_{s=t}^{\infty}\left[1+\frac{\rho}{\left(1-\tau_{e}\right)}\right]^{-(s-t+1)}\left(\frac{\left(1-\tau_{d}\right)}{\left(1-\tau_{e}\right)} D_{s}+R_{s}\right),
$$

\footnotetext{
${ }^{13}$ For the interested reader, the discount factor $\left[1+\rho /\left(1-\tau_{e}\right)\right]^{-1}$ can be explained as follows. An increase in either dividends or share repurchases translates into a higher end-of-period cum-dividend share price, i.e., a capital gain. The market value of a marginal capital gain is $\left(1-\tau_{e}\right)$ at the end of a period, which translates into a beginning-ofperiod value of $\left(1-\tau_{e}\right) /(1+\rho)$. However, when this amount is capitalized into the firm's beginning-of-period market value, it not only increases the stock price, it also reduces the future tax liability of a marginal investor, since the stock now appreciates by $\left(1-\tau_{e}\right) /(1+\rho)$ less. This creates a future tax savings of $\tau_{e}\left(1-\tau_{e}\right) /(1+\rho)$, with a present value of $\tau_{e}\left(1-\tau_{e}\right) /(1+\rho)^{2}$. This increases the firm's stock price once again, and further reduces the marginal investor's future tax liability. Continuing this process indefinitely produces an infinite sequence of progressively smaller tax savings with present value $\left[\tau_{e}\left(1-\tau_{e}\right)\right] /\left[(1+\rho)\left(1+\rho-\tau_{e}\right)\right]$. When this sum is added to the discounted value of the original capital gain (i.e., $\left.\left(1-\tau_{e}\right) /(1+\rho)\right)$, we arrive at the discount factor in Equation 5
} 
by applying the transversality condition:

$$
\lim _{T \rightarrow \infty}\left[1+\frac{\rho}{\left(1-\tau_{e}\right)}\right]^{-T} V_{T}=0,
$$

which is necessary for optimality.

Equation 6 is the intrinsic value of equity when shareholders face taxes on dividends and capital gains (also referred to as the "market value" in this paper), and is useful for describing the corporate payout puzzle. Recall that firms use net income to pay dividends, repurchase shares, and/or make capital investments. It is usually assumed that firms can repurchase any quantity of equity at its intrinsic value when capital markets are perfect (i.e., complete, competitive, frictionless, and free of informational asymmetries). This assumption is inconsistent with actual capital-gains taxation, however - with important implications below - but for the sake of describing the payout puzzle, assume that it holds for the moment, i.e., that $R_{s}$ equals the amount of money spent repurchasing equity in period $s$ (denoted by $A_{s}$ henceforth). In this case, a firm's period- $s$ budget constraint is:

$$
\left(1-\tau_{c}\right) \pi\left(K_{s}\right)=D_{s}+R_{s}+I_{s} .
$$

It becomes immediately obvious from Equations 6 and 7 that setting $D_{s}=0 \forall s$ is optimal whenever $\tau_{d}>\tau_{e}$, since any marginal substitution of dividends for share repurchases in period $s \geq t$ raises period- $t$ value by $\left[1+\rho /\left(1-\tau_{e}\right)\right]^{-(s-t+1)}\left(\tau_{d}-\tau_{e}\right) /\left(1-\tau_{e}\right)>0$. Given that $\tau_{d}$ is generally greater than $\tau_{e}$ (see Table 1 of Section 3 ) the payout puzzle follows immediately 14

Since $D_{s}=0 \forall s$ is empirically violated (see Figures 1 and 2 of Section 3 ) the perfect-information literature has typically appealed to either: exogenous factors that place lower bounds on dividends (either explicit or implicit), such as the "intrinsic value of dividends" assumption in Shefrin and Statman (1984); or exogenous factors that place upper bounds on share repurchases, such as appealing to Section 302 of the Internal Revenue Code. The former explanation has share repurchases (share issuances) as the marginal form of payout (funding), and is commonly referred to as the Traditional view or Conventional view, while the second explanation has dividends (retentions) as the marginal form of payout (funding), and is commonly referred to as the New view or Tax Capitalization view. The Traditional view is typically more reasonable for young firms, while the New view is more reasonable for mature firms. These frameworks are discussed further below.

In contrast to these explanations, the one pursued here does not require exogenous bounds on dividends or share repurchases. The crucial assumption is that capital gains are taxed upon realization rather than accrual. In this way, the paper provides a self-contained model of firmvalue maximization that permits dividend payments within a perfect-information context. This is

\footnotetext{
${ }^{14}$ Conversely, if $\tau_{d}<\tau_{e}$, firm-value maximization entails unlimited equity issuance and unlimited dividend payments. Only in the special case when $\tau_{d}=\tau_{e}$ could there be an interior solution.
} 
accomplished by deriving the firm's "repurchase function" (the mapping from $A_{t}$ into $R_{t}$ ), which is based on shareholder-wealth maximization within a realization-based capital-gains tax system. This is done next.

\subsection{Shareholders and the Mapping from $A_{t}$ into $R_{t}$}

Shareholders are identical in all respects except for their investment horizons and level of accrued capital gains on firm equity. The mechanisms that produce each source of heterogeneity are not modeled in the current paper, but are not controversial either. The former depends on factors such as retirement planning and portfolio management, while the latter depends on the timing of past share purchases. Consistent with the notion of a "desired holding period," shareholders in the model reinvest all dividend income in the same (or identical) stock, and fully liquidate their equity positions upon reaching that period 15 In this way, shareholders seek to maximize the amount of after-tax wealth they have upon reaching their investment horizons.

Pursuing this objective within a realization-based capital-gains tax system produces the lock-in effect described above: i.e., the incentive to postpone the sale of equity with an accrued capital gain and non-zero holding period. The lock-in effect is well described by previous studies, but the following example is helpful for illustrating its mechanism; it is also a good starting point for deriving the mapping from $A_{t}$ into $R_{t}$.

Suppose that an investor owns $\$ 10$ of stock with a tax basis of $\$ 5$, and wishes to liquidate this position in 10 periods. If the tax rate on dividends and realized capital gains are both $20 \%$, and the stock yields a $5 \%$ dividend and a $5 \%$ capital gain in each period, then the investor's equity position is worth $\$ 10.9$ at the end of period 1, and her tax basis becomes $\$ 5.4$ (due to the dividend reinvestment). These values are documented in Row 1 of Table 2, which reports the time series of: equity value, tax basis, income from after-tax dividends, and income from accrued capital gains. When this procedure is repeated over the subsequent 9 periods, the investor's equity position reaches $\$ 23.67$ in gross value, while her tax basis reaches $\$ 11.08$, as reported in Row 10 of Table 2. Finally, due to the capital-gains tax liability of $\$ 2.52$ upon liquidation, the investor's after-tax wealth is $\$ 21.15{ }^{16}$ Conversely, suppose that the same investor liquidates her equity position immediately, pays the capital-gains tax, reinvests the net proceeds in the same stock, and liquidates the new position after 10 periods. The initial equity sale and reinvestment provides $\$ 9$ of equity and a $\$ 9$ tax basis, which appreciate to $\$ 21.31$ and $\$ 14.47$ at the end of period 10 , respectively (see Table 3). This provides after-tax wealth of $\$ 19.94$, which is $\$ 1.21$ lower than before (or $5.7 \%$ ).

This disparity in after-tax wealth between the two scenarios is attributable to the foregone

\footnotetext{
${ }^{15}$ The full-reinvestment assumption is not necessary for the main results, but it seems natural.

${ }^{16}$ The capital-gains tax liability is $20 \%$ of the position's capital gain, which is equal to the position's selling price $(\$ 23.67)$ minus the tax basis $(\$ 11.08)$.
} 
Table 2. Example: Stock Price and Tax Basis when Equity is Held

\begin{tabular}{|c|c|c|c|c|c|c|}
\hline \multirow[b]{2}{*}{ Period } & \multicolumn{2}{|c|}{ Beginning of Period } & \multicolumn{4}{|c|}{ End of Period } \\
\hline & $\begin{array}{c}\text { Equity Value } \\
\text { (1) }\end{array}$ & $\begin{array}{c}\text { Tax Basis } \\
(2)\end{array}$ & $\begin{array}{c}\text { Capital Gain } \\
\text { (3) }\end{array}$ & $\begin{array}{l}\text { Dividend } \\
\text { (4) }\end{array}$ & $\begin{array}{c}\text { Equity Value } \\
\text { (5) }\end{array}$ & $\begin{array}{c}\text { Tax Basis } \\
(6)\end{array}$ \\
\hline 1 & 10.00 & 5.00 & 0.50 & 0.40 & 10.90 & 5.40 \\
\hline 2 & 10.90 & 5.40 & 0.55 & 0.44 & 11.88 & 5.84 \\
\hline 3 & 11.88 & 5.84 & 0.59 & 0.48 & 12.95 & 6.31 \\
\hline 4 & 12.95 & 6.31 & 0.65 & 0.52 & 14.12 & 6.83 \\
\hline 5 & 14.12 & 6.83 & 0.71 & 0.56 & 15.39 & 7.39 \\
\hline 6 & 15.39 & 7.39 & 0.77 & 0.62 & 16.77 & 8.01 \\
\hline 7 & 16.77 & 8.01 & 0.84 & 0.67 & 18.28 & 8.68 \\
\hline 8 & 18.28 & 8.68 & 0.91 & 0.73 & 19.93 & 9.41 \\
\hline 9 & 19.93 & 9.41 & 1.00 & 0.80 & 21.72 & 10.21 \\
\hline 10 & 21.72 & 10.21 & 1.09 & 0.87 & 23.67 & 11.08 \\
\hline
\end{tabular}

This table reports the time series of a hypothetical investor's equity value and tax basis when the position is held for 10 periods. The tax rate on dividends and realized capital gains are both $20 \%$, the stock's dividend and capital-gain yield are both $5 \%$, the original equity position is worth $\$ 10$, and the original tax basis is $\$ 5$. Column 3 (end of period capital gain) is equal to Column 1 (beginning of period equity value) multiplied by the capital-gain yield. Column 4 (end of period net-of-tax divided) is equal to Column 1 multiplied by the after-tax dividend yield, which itself is equal to the gross dividend yield multiplied by one minus the dividend tax rate. Column 5 (end of period equity value) is equal to the sum of Columns 1 , 3, and 4 . Column 6 (end of period tax basis) is equal to the sum of Column 2 (beginning of period tax basis) and Column 4.

Table 3. Example: Stock Price and Tax Basis when the Proceeds of an Equity Sale are Reinvested

\begin{tabular}{|c|c|c|c|c|c|c|}
\hline \multirow[b]{2}{*}{ Period } & \multicolumn{2}{|c|}{ Beginning of Period } & \multicolumn{4}{|c|}{ End of Period } \\
\hline & $\begin{array}{c}\text { Equity Value } \\
\text { (1) }\end{array}$ & $\begin{array}{c}\text { Tax Basis } \\
(2)\end{array}$ & $\begin{array}{c}\text { Capital Gain } \\
(3)\end{array}$ & $\begin{array}{l}\text { Dividend } \\
\text { (4) }\end{array}$ & $\begin{array}{c}\text { Equity Value } \\
\text { (5) }\end{array}$ & $\begin{array}{c}\text { Tax Basis } \\
(6)\end{array}$ \\
\hline 1 & 9.00 & 9.00 & 0.45 & 0.36 & 9.81 & 9.36 \\
\hline 2 & 9.81 & 9.36 & 0.49 & 0.39 & 10.69 & 9.75 \\
\hline 3 & 10.69 & 9.75 & 0.53 & 0.43 & 11.66 & 10.18 \\
\hline 4 & 11.66 & 10.18 & 0.58 & 0.47 & 12.70 & 10.65 \\
\hline 5 & 12.70 & 10.65 & 0.64 & 0.51 & 13.85 & 11.15 \\
\hline 6 & 13.85 & 11.15 & 0.69 & 0.55 & 15.09 & 11.71 \\
\hline 7 & 15.09 & 11.71 & 0.75 & 0.60 & 16.45 & 12.31 \\
\hline 8 & 16.45 & 12.31 & 0.82 & 0.66 & 17.93 & 12.97 \\
\hline 9 & 17.93 & 12.97 & 0.90 & 0.72 & 19.55 & 13.69 \\
\hline 10 & 19.55 & 13.69 & 0.98 & 0.78 & 21.31 & 14.47 \\
\hline
\end{tabular}

This table reports the time series of a hypothetical investor's equity value and tax basis when the equity position is immediately sold, and the proceeds are promptly reinvested. The tax rate on dividends and realized capital gains are both $20 \%$, the stock's dividend and capital-gain yield are both $5 \%$, the original equity position is worth $\$ 9$ (after the reinvestment), and the original tax basis is $\$ 9$ (again, after the reinvestment). Column 2 (end of period capital gain) is equal to Column 1 (beginning of period equity value) multiplied by the capital-gain yield. Column 4 (end of period net-of-tax divided) is equal to Column 1 multiplied by the after-tax dividend yield, which itself is equal to the gross dividend yield multiplied by one minus the dividend tax rate. Column 5 (end of period equity value) is equal to the sum of Columns 1, 3, and 4. Column 6 (end of period tax basis) is equal to the sum of Column 2 (beginning of period tax basis) and Column 4. 
income that would have accrued on the investor's gross wealth used to pay the capital-gains tax in period 1 (i.e., the $\$ 1$ ). This amounts to $\$ 0.61$ of foregone after-tax dividend income and $\$ 0.61$ of foregone after-tax capital-gains income. In general, the marginal differential in after-tax wealth between the two scenarios (the first minus the second) is:

$$
\Omega(H, \beta)=\left\{\begin{array}{cl}
\tau_{g}(1-\beta)\left[\left(1-\tau_{g}\right) r_{g}+\left(1-\tau_{d}\right) r_{d}\right] \sum_{h=1}^{H}\left(1+r_{g}+\left(1-\tau_{d}\right) r_{d}\right)^{h-1} & \text { if } H>0 \\
0 & \text { if } H=0
\end{array}\right.
$$

where $\beta$ is the investor's tax basis as a fraction of equity's price, $r_{d}$ and $r_{g}$ are the gross rates of return from dividends and accrued capital gains, respectively, and $H \geq 0$ is the investor's desired holding period (in 1-period intervals). See Appendix B for a derivation of this result. Note that $\beta<1$ indicates a capital gain, while $\beta>1$ indicates a capital loss. Furthermore, $\beta=0$ is the limiting case when the entire equity value is a capital gain. The function $\Omega(H, \beta)$ has the following five relevant properties:

1. $\Omega(H, \beta) \geq 0$ if $\beta<1$ : shareholders have a disincentive to sell equity with a capital gain,

2. $\Omega(H, \beta) \leq 0$ if $\beta>1$ : shareholders have an incentive to sell equity with a capital loss ${ }^{17}$

3. $\Omega(H, 1)=0$ if $\beta=1$ : shareholders are indifferent between selling/retaining equity in the absence of a capital gain or loss,

4. $\Omega_{\beta}^{\prime}(H, \beta) \leq 0$ : the wealth differential is decreasing in the investor's tax basis (increasing in the capital gain), where $\Omega_{\beta}^{\prime}(\cdot)$ is the derivative of $\Omega(H, \beta)$ with respect to $\beta$,

5. $\Omega(H+1, \beta)-\Omega(H, \beta) \geq 0$ : the wealth differential is increasing in the investor's desired holding period.

Given the properties of $\Omega(H, \beta)$, investors with a capital loss are happy to liquidate their equity position immediately, while those with a capital gain are not indifferent between: 1 ) liquidating their equity position at the current market price, and 2) retaining their position for a desired number of periods. In order to create such indifference, an investor must be offered a "lock-in premium" in addition to equity's market price. This premium is investor-specific owing to differences in tax bases and desired holding periods, and is characterized by the following function (as a fraction of equity's market price):

$$
L(H, \beta)=\left\{\begin{array}{cc}
(1-\beta) \frac{\tau_{g}}{1-\tau_{g}}\left[\frac{\Omega(H, \beta)}{\Omega(H, \beta)+\tau_{g}(1-\beta)}\right] & \text { if } \beta<1, \\
0 & \text { if } \beta \geq 1
\end{array}\right.
$$

\footnotetext{
${ }^{17}$ The tax refund from selling equity with a capital loss requires offsetting income (e.g., a capital gain on other assets).
} 
where $\Omega(H, \beta)$ is from Equation 8. See Appendix $\mathrm{C}$ for a derivation of this result. As with $\Omega(H, \beta)$, the lock-in premium $L(H, \beta)$ is increasing in $H$ and decreasing in $\beta$. When shareholders are offered this premium (in addition to equity's intrinsic value) they become indifferent between selling equity back to the firm and holding it for a desired number of periods. This indifference makes $L(H, \beta)$ a pure cost from the perspective of firms and shareholders. The only beneficiary is the tax authority via accelerated realizations.

It will be assumed throughout that each investor is paid their specific lock-in premium when selling equity back to a firm, which is the minimum compensation that a wealth-maximizing shareholder is willing to accept 18 This minimizes the cost of repurchasing equity while maintaining shareholder rationality, which in turn, reduces the likelihood that dividends are paid in equilibrium. As such, the current pricing assumption is taken to be a "worst-case scenario" for dividends: when dividend payments are optimal using this pricing assumption, they should remain optimal when shareholders extract economic rents through bargaining and/or other strategic behavior. But the reverse is not necessarily true.

Recall that shareholders are heterogeneous with respect to $H$ and $\beta$; this gives rise to a diverse set of investors types. Denote the density of this set by $f(H, \beta)$, which is assumed to be distributed discretely over $H$ (in one-period intervals) and continuously over $\beta$. Furthemore, assume that $f(H, \beta)$ has full support over the domain $\{H, \beta \mid 0 \leq H \leq \bar{H}, 0 \leq \beta \leq \bar{\beta}\}$ for some $\bar{H}>0$ and $\bar{\beta}>0$, and that $f(H, \beta)$ is constant across time. These last two assumptions are relaxed in Section 5 when the shareholder distribution is endogenized. But for the time-being, it is convenient to assume that $f(H, \beta)$ has reached a long-run steady-state ${ }^{19}$ and has full support 20

\subsection{The Repurchase Function}

Now that we have the lock-in premium function $L(H, \beta)$, the shareholder density $f(H, \beta)$, and a pricing assumption, we can derive the mapping from $A_{t}$ into $R_{t}$. To make this derivation straightforward, first decompose the shareholder density $f(H, \beta)$ into $\bar{H}+1$ sections corresponding to each possible desired holding period from 0 to $\bar{H}$, and denote these by $f^{H}(\beta)$. Second, designate a

\footnotetext{
${ }^{18}$ This assumption is consistent with Ikenberry et al. (1995), which documents the gradual increase in share prices during a typical repurchase program: specifically, Ikenberry et al. (1995) shows that a stock's cumulative abnormal return (CAR) gradually increases over the three-year period following an open-market repurchase announcement, a time during which most repurchase activity seems to take place according to Stephens and Weisbach (1998). Chan et al. (2010) also documents this pattern for CARs during most of the two-year period following a repurchase announcement.

${ }^{19}$ As shown in Section 5 share repurchases neccesarilly alter the shareholder distribution by removing investors with relatively low lock-in premiums (i.e., those with short holding periods and/or few capital gains). However, an approximately-constant shareholder distribution is still possible given countervailing dynamics: a shareholder's desired holding period becomes progressively shorter as time passes, and shareholder turnover between successive repurchase programs creates a new set of shareholders with relatively low capital gains.

${ }^{20}$ This assumption simply ensures a continuously-differentiable mapping from $A_{t}$ into $R_{t}$.
} 
value of $\beta$ for each desired holding period, and denote these by $\beta(H)$. Finally, note that firmvalue maximization entails repurchasing equity at the lowest cost, i.e., from the set of shareholders with the lowest lock-in premiums ${ }^{21}$ Therefore, a firm's repurchase function is derived by selecting $\beta(H), H=0,1, . ., \bar{H}$ to maximize:

$$
R_{t}=\max _{\{\beta(H)\}}\left[\sum_{H=0}^{\bar{H}} \int_{\beta(H)}^{\bar{\beta}} f^{H}(\beta) d \beta\right] V_{t+1},
$$

subject to:

$$
A_{t}=\left[\sum_{H=0}^{\bar{H}} \int_{\beta(H)}^{\bar{\beta}}[1+L(H, \beta)] f^{H}(\beta) d \beta\right] V_{t+1} .
$$

These two equations state that firms maximize the total mass of repurchased equity subject to spending $A_{t}$ on the repurchase program. In the absence of lock-in premiums (i.e., $L(H, \beta)=0 \forall H$ and $\forall \beta$ ) - which is typically assumed - the repurchase function collapses to $R\left(A_{t}\right)=A_{t}$. However, when lock-in premiums are characterized by Equation 9, firms pay investor-specific premiums to repurchase equity, and thus $R\left(A_{t}\right) \leq A_{t}$. This property of the repurchase function is stated in Proposition 1 along with three others.

Proposition 1 The repurchase function has the following 4 properties for any shareholder density with full support:
1. $R\left(A_{t}\right) \leq A_{t}$,
2. $R^{\prime}\left(A_{t}\right)>0$,
3. $R^{\prime \prime}\left(A_{t}\right) \leq 0$,
and
4. $R\left(A_{t}\right) \in C^{1}$.

See Appendix $E$ for a proof of these results.

Proposition 1 states that $R\left(A_{t}\right)$ is increasing in the amount spent and below (possibly weakly) the $45^{\circ}$ line. As more equity is repurchased, the marginal shareholder's lock-in premium increases; it follows that $R\left(A_{t}\right)$ is globally concave in the amount spent. Finally, the repurchase function is continuously differentiable.

With the repurchase function now derived, we can return to the firm's maximization problem next.

\subsection{The Firm's Problem}

Recall that firms seek to maximize their current market value by selecting a sequence of dividend payments, share repurchases, and capital investments from the feasible set. Formally, firms seek to:

\footnotetext{
${ }^{21}$ Dittmar and Field (2015) provides evidence that firms typically repurchase shares in a cost-effective manner.
} 


$$
\max _{\left\{D_{s}, A_{s}, I_{s}\right\}_{s=t}^{\infty}} V_{t}=\sum_{s=t}^{\infty}\left[1+\frac{\rho}{\left(1-\tau_{e}\right)}\right]^{-(s-t+1)}\left(\frac{\left(1-\tau_{d}\right)}{\left(1-\tau_{e}\right)} D_{s}+R_{s}\right),
$$

subject to the repurchase function:

$$
R_{s}=R\left(A_{s}\right)
$$

the per-period budget constraint:

$$
\left(1-\tau_{c}\right) \pi\left(K_{s}\right)=D_{s}+A_{s}+I_{s}
$$

the law of motion for capital:

$$
K_{s+1}=K_{s}+I_{s},
$$

and the non-negative dividend constraint:

$$
D_{s} \geq 0 \text {. }
$$

The Karush-Kuhn-Tucker necessary conditions for optimality are as follows (for any period $s \geq t$ ):

$$
\begin{gathered}
{\left[1+\frac{\rho}{\left(1-\tau_{e}\right)}\right]^{-(s-t+1)} \frac{\left(1-\tau_{d}\right)}{\left(1-\tau_{e}\right)}-\lambda_{s}^{B}-\lambda_{s}^{D}=0} \\
{\left[1+\frac{\rho}{\left(1-\tau_{e}\right)}\right]^{-(s-t+1)} R^{\prime}\left(A_{s}\right)-\lambda_{s}^{B}=0} \\
\lambda_{s}^{B}\left(1-\tau_{c}\right) \pi^{\prime}\left(K_{s}\right)-\lambda_{s}^{K}+\lambda_{s-1}^{K}=0 \\
-\lambda_{s}^{B}-\lambda_{s}^{K}=0 \\
\lambda_{s}^{i} \geq 0 \text { for } i=B, K, D \\
\lambda_{s}^{D} D_{s}=0
\end{gathered}
$$

where $\lambda_{s}^{B}, \lambda_{s}^{K}$, and $\lambda_{s}^{D}$ are the period-s Lagrange multipliers on the budget constraint, law of motion for capital, and non-negative dividend constraint, respectively.

\subsection{Steady-State Payout}

To derive the steady-state level of payout, and to show that dividends are consistent with firm-value maximization, use Equations 12 and 13 to get: 


$$
R^{\prime}\left(A_{s}^{*}\right)=\frac{\left(1-\tau_{d}\right)}{\left(1-\tau_{e}\right)}+\lambda_{s}^{D}
$$

where $A_{s}^{*} \geq 0$ is the equilibrium amount spent repurchasing shares in period $s$. This equation states that equilibrium share repurchases have a marginal value equal to that of dividends, plus the shadow value of relaxing the non-negative dividend constraint $\lambda_{s}^{D}$, which is weakly positive. From Equations 16 and $17, \lambda_{s}^{D}$ may take on one of two qualitatively-distinct values in period $s$ :

1. $\lambda_{s}^{D}>0\left(\right.$ when $\left.D_{s}^{*}=0\right)$,

2. $\lambda_{s}^{D}=0\left(\right.$ when $\left.D_{s}^{*}>0\right)$,

where $D_{s}^{*}$ is the equilibrium level of dividends in period $s$.

The first of these $\left(\lambda_{s}^{D}>0\right)$ prevails whenever the marginal value of a share repurchase exceeds that of a dividend for the firm's entire payout. This is usually the case in perfect-information models since $R^{\prime}\left(A_{s}\right)=1>\left(1-\tau_{d}\right) /\left(1-\tau_{e}\right) \forall A_{s}$. However, as shown in Section 4.2, the repurchase function's first derivative is not equal to unity for all $A_{s}$. Rather, it is strictly less than unity whenever a marginal shareholder has strictly-positive capital gains and a non-zero holding period. Furthermore, since marginal lock-in premiums increase as more equity is repurchased, the marginal value of a share repurchase declines monotonically as more equity is sought (property 3 of Proposition 1). Therefore, it becomes entirely possible that $R^{\prime}\left(A_{s}\right)$ falls below $\left(1-\tau_{d}\right) /\left(1-\tau_{e}\right)$ as $A_{s}$ increases. Management prevents this from happening in equilibrium, however, by switching from share repurchases to dividend payments when $R^{\prime}\left(A_{s}\right)=\left(1-\tau_{d}\right) /\left(1-\tau_{e}\right)$. This is captured by the second case above $\left(\lambda_{s}^{D}=0\right)$. In this case $R^{\prime}\left(A_{s}^{*}\right)=\left(1-\tau_{d}\right) /\left(1-\tau_{e}\right)$ and $D_{s}^{*}>0$, thus providing the perfect-information explanation for dividend payments.

These results also help explain why stock prices typically increase during repurchase programs, and why stock prices fail to react when no equity is repurchased following a repurchase announcement. Regarding the first, the model suggests that share repurchases typically require the payment of lock-in premiums. These, in turn, place upward pressure on stock prices. Regarding the second, the model suggests that stock prices are largely independent of lock-in premiums in the absence of actual buybacks, since ordinary investors are unwilling to pay these premiums given their exogenous required rate of return (i.e., $\rho$ ). Repurchasing firms are the only agents willing to pay them, since their outside option is paying a tax-disadvantaged dividend. The first result is consistent with Ikenberry et al. (1995) and Chan et al. (2010), while the second result is consistent with Stephens and Weisbach (1998). 


\subsection{Comparative Statics}

The last section established that dividends are consistent with firm-value maximization. This section discusses some of the factors that make dividend payments more or less likely. Specifically: the repurchase function's curvature, the level of total payout, and the marginal value of dividends. These comparative statics are presented in a simplified format below - with an exogenous repurchase function - for ease of exposition, and are replicated numerically in Appendix F, where the repurchase function's endogeneity is explicitly accounted for; the qualitative results are identical. These comparative statics showcase some of the model's similarities with observed corporate payout.

To begin with, the base-case scenario is depicted in Panel 1 of Figure 3 (denoted with a $B$ subscript). In this case, marginal share repurchases are more valuable than marginal dividends for the firm's entire payout (represented by the vertical dashed line $T P_{B}=$ total payout). As such, repurchases constitute the marginal and only form of payout. This scenario corresponds to case 1 of Section 4.5, i.e.:

$$
\lambda_{s}^{D}>0, R^{\prime}\left(T P_{B}\right)>\frac{\left(1-\tau_{d}\right)}{\left(1-\tau_{e}\right)}, \text { and } D_{s}^{*}=0,
$$

from Equation 18 .

The first comparative static (denoted with a $C 1$ subscript) adds a greater degree of curvature to the repurchase function. This arises when marginal lock-in premiums grow at a faster rate as equity is repurchased, which, in turn, is due to a reduction in the mass of shareholders with relatively low accrued capital gains and/or short holding periods. This can arise when: the average holding period increases; the average tax basis decreases; or the variance of either declines, as shown in the numerical examples of Appendix $\mathrm{F}$. This additional curvature causes $R^{\prime}(A)$ to decline at a faster rate over the relevant range of payout, which reduces the benefit of share repurchases, and increases the likelihood that dividends become the marginal form of payout. This scenario is depicted in Panel 2 of Figure 3, where the repurchase function's first derivative is pivoted downward. In this case, firms optimally spend $A_{C 1}^{*}<A_{B}^{*}$ repurchasing equity, while spending the remaining $D_{C 1}^{*}=T P_{C 1}-A_{C 1}^{*}>0$ of total payout on dividends (where $T P_{C 1}=T P_{B}$ ). This comparative static is consistent with Stephens and Weisbach (1998), which shows that firms repurchase less equity following a stock-price appreciation - i.e., a reduction in the mass of shareholders with relatively high $\beta$. It is also consistent with Gaspar et al. (2012), which shows that firms repurchase less equity as average holding periods increase.

The second comparative static (denoted with a $C 2$ subscript) involves increasing the firm's total payout from $T P_{B}$ to $T P_{C 2}>T P_{B}$. This results in a higher number of repurchased shares - since $R^{\prime}\left(T P_{B}\right)>\left(1-\tau_{d}\right) /\left(1-\tau_{e}\right)$, i.e., the marginal value of a share repurchase exceeds that of a dividend at $A_{C 2}=T P_{B}$ - and a higher probability that marginal lock-in premiums become 

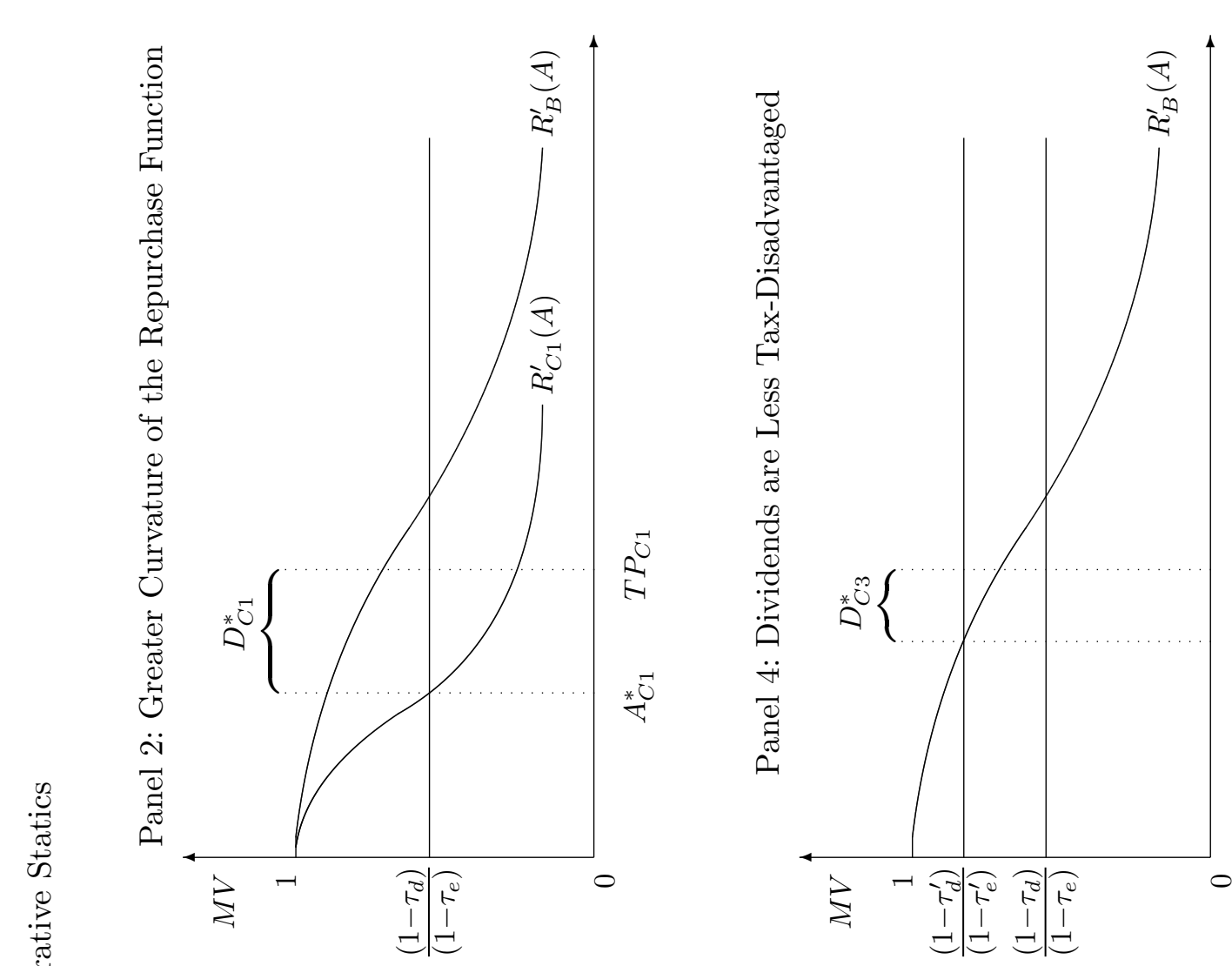

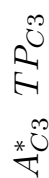

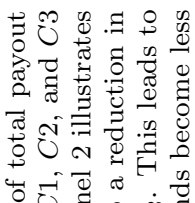

ठ ठ

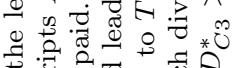

का

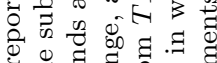

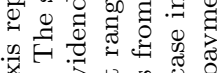

议

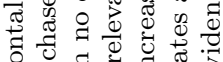

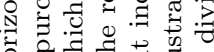

¿

-

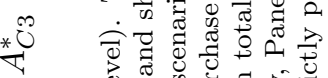

Q

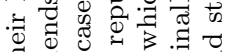

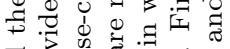

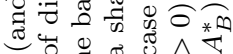

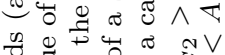

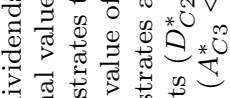

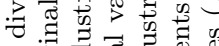

定

2

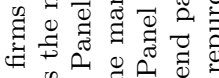
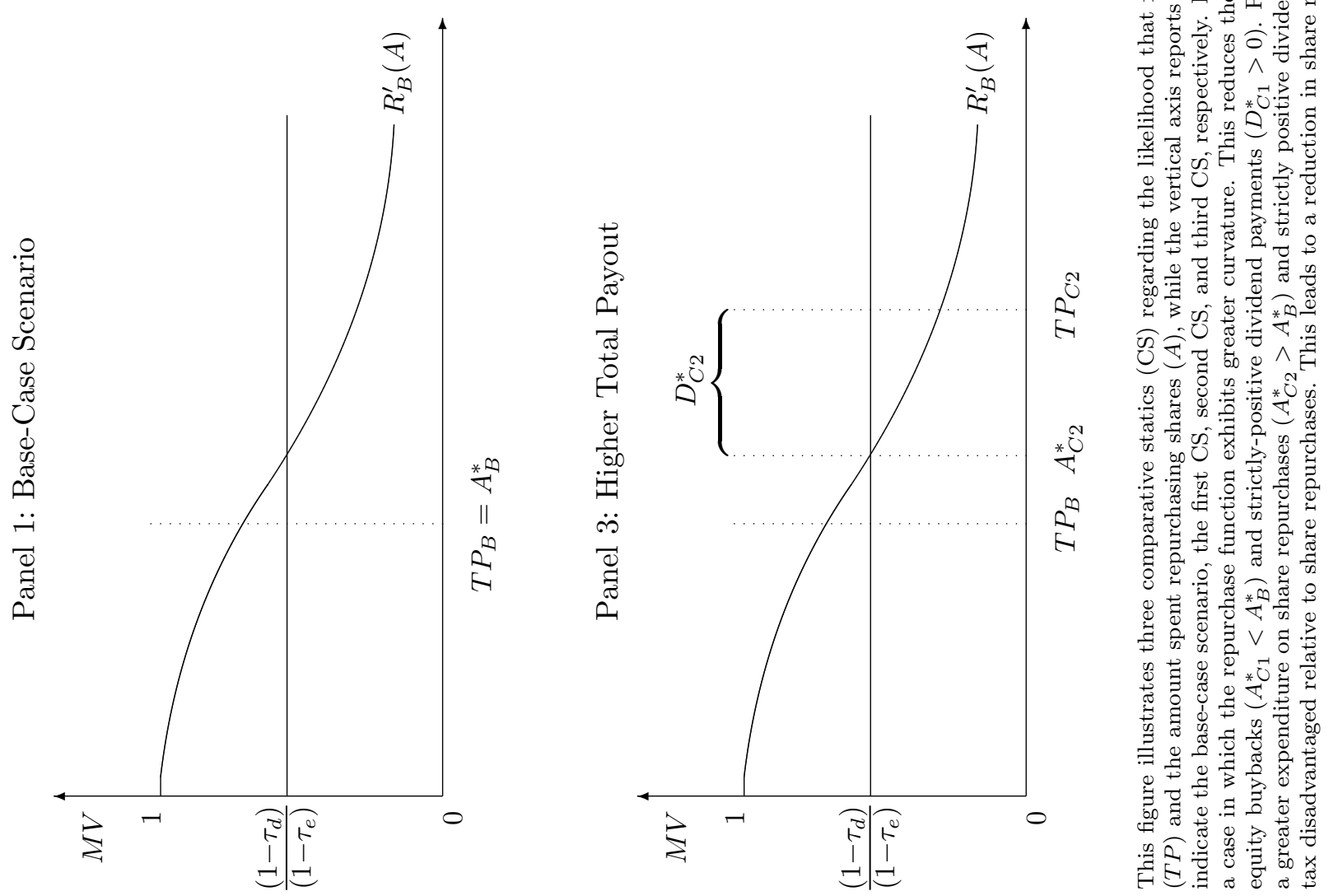
sufficiently large that dividends are paid in equilibrium, i.e., $R^{\prime}\left(T P_{C 2}\right)<\left(1-\tau_{d}\right) /\left(1-\tau_{e}\right)$. This particular case is depicted in Panel 3 of Figure 3, where the higher expenditure on share repurchases, from $A_{B}^{*}=T P_{B}$ to $A_{C 2}^{*}>A_{B}^{*}$, reduces their marginal value from $R^{\prime}\left(A_{B}^{*}\right)>\left(1-\tau_{d}\right) /\left(1-\tau_{e}\right)$ to $R^{\prime}\left(A_{C 2}^{*}\right)=\left(1-\tau_{d}\right) /\left(1-\tau_{e}\right)$, and as a result, dividends are paid $\left(D_{C 2}^{*}=T P_{C 2}-A_{C 2}^{*}>0\right)$. This comparative static is consistent with Fama and French (2001) and Denis and Osobov (2008), which show that dividend payments are more likely among highly-profitable firms (e.g., Fama and French, 2001 reports that dividend-paying firms have an average earnings-to-assets ratio of $7.82 \%$, versus $5.37 \%$ for non-payers).

The third comparative static (denoted with a $C 3$ subscript) involves increasing $\left(1-\tau_{d}\right) /\left(1-\tau_{e}\right)$, i.e., the marginal value of dividends, while holding the firm's repurchase function constant ${ }^{22}$ This happens when: the dividend tax rate $\tau_{d}$ declines, the statutory tax rate on capital gains $\tau_{g}$ increases, and/or the ratio of effective-to-statutory tax rates on capital gains $\tau_{e} / \tau_{g}$ increases. This causes $R^{\prime}(A)$ to fall below $\left(1-\tau_{d}\right) /\left(1-\tau_{e}\right)$ at a lower value of $A$, which raises the likelihood that $R^{\prime}\left(T P_{C 3}\right)<$ $\left(1-\tau_{d}\right) /\left(1-\tau_{e}\right)$, and that dividends are paid in equilibrium (where $T P_{C 3}=T P_{B}$ ). This particular case is depicted in Panel 4 of Figure 3 - where $R^{\prime}\left(A_{C 3}^{*}\right)=\left(1-\tau_{d}\right) /\left(1-\tau_{e}\right), A_{C 3}^{*}<A_{B}^{*}$, and $D_{C 3}^{*}=T P_{C 3}-A_{C 3}^{*}>0-$ and is consistent with Poterba (2004), Chetty and Saez (2005, 2006), Brown et al. (2007), and Moser (2007), which all show that firms are more likely to pay dividends, and/or pay higher dividends, when the ratio $\tau_{d} / \tau_{g}$ decreases.

\subsection{The Cost of Capital}

Consistent with the Tax-Capitalization view discussed in Section 4.1, dividend taxes do not distort the steady-state level of capital, whereas the corporate-profits tax and the capital-gains tax do. To see this, use Equations 13 and 15 of Section 4.4 to derive the period $s>t$ shadow value of capital:

$$
\lambda_{s}^{K}=\left[1+\frac{\rho}{\left(1-\tau_{e}\right)}\right]^{-(s-t+1)} R^{\prime}\left(A^{*}\right) .
$$

Furthermore, note that capital's shadow value in period $s-1$ is:

$$
\lambda_{s-1}^{K}=\left[1+\frac{\rho}{\left(1-\tau_{e}\right)}\right] \lambda_{s}^{K}
$$

in a stead-state. Finally, after substituting Equations 15, 19, and 20 into Equation 14 we have the firm's equilibrium hurdle rate:

$$
\pi^{\prime}\left(K^{*}\right)=\frac{\rho}{\left(1-\tau_{c}\right)\left(1-\tau_{e}\right)} .
$$

This equation is independent of $\tau_{d}$, and is increasing in both $\tau_{c}$ and $\tau_{e}$. The independence of $K^{*}$

\footnotetext{
${ }^{22}$ In practice, changes in $\tau_{d}$ and/or $\tau_{g}$ affect the repurchase function's curvature, which is ignored in the current exercise for simplicity. See Appendix $\mathrm{F}$ for a qualitatively-identical comparative static in which the repurchase function is endogenously determined with respect to $\tau_{d}$ and $\tau_{g}$ according to Equations 9,10 and 11 .
} 
and $\tau_{d}$ is inconsistent with the Traditional view, where higher (lower) dividend tax rates decrease (increase) the steady-state capital stock. It is unclear which of the two conclusions has greater empirical support, as discussed in Auerbach (2002).

\section{Endogenous Shareholder Distribution}

This section endogenizes the shareholder distribution, and therefore, the repurchase function. This serves two purposes. First, it illustrates that dividends are more of a certainty in the current model than a mere possibility for long-lived firms. And second, it provides additional support for the model by matching the tendency of firms to use share repurchases for early payout, and to add dividend payments later on, especially for stable distributions. This numerical exercise is not meant to capture many aspects of reality in a meaningful way, but rather, to provide a straight-forward exposition of the mechanism's dynamics. That said, the approach used herein can be adapted for more rigorous calibration exercises going forward.

Assume that a group of investors purchase a firm at the beginning of period 1 . As such, they start off with no capital gains $(\beta=1)$. These investors are identical in all respects except for their desired holding periods, which vary from 1 to $\bar{H}$. Management's problem is to select a sequence of dividend payments $\left(\left\{D_{t}\right\}_{t=1}^{\infty}\right)$ and share repurchases $\left(\left\{A_{t}\right\}_{t=1}^{\infty}\right)$ to maximize firm value, subject to a constant level of total payout (equal to 1 in every period) 23 In keeping with the model's dynamic nature, every shareholder's desired holding period is reduced by 1 at the end of a period. This implies that all remaining shareholders at the end of period $\bar{H}$ have desired holding periods of 0 , and as such, the firm is sold to a new group of investors with identical characteristics at the beginning of period $\bar{H}+12$ These assumptions facilitate a numerical solution by having: 1) a tractable dynamic shareholder distribution, and 2) a firm value that repeats every $\bar{H}$ periods.

The model's parameterization is as follows. The statutory tax rate on dividends and realized capital gains are both $20 \%$. The effective tax rate on accrued capital gains is set to $80 \%$ of the statutory rate (i.e., 16\%). Desired holding periods are initially set from 1 to 150 periods, inclusive, and each of these is allocated an equal mass of shareholder density at the beginning of period 1 (this becomes endogenous thereafter). Shareholders require an after-tax rate of return equal to 5\%, and as stated before, total payout is unity in every period. These parameter values are reported

\footnotetext{
${ }^{23}$ Payout is exogenous in the current exercise. This simplifies the analysis - there is no need to specify the firm's profit function, and a degree of complexity is removed from the numerical solution - without perverting the model's true dynamics to a large degree: the marginal value of capital is usually constant (equal to that of dividends for $83 \%$ of the periods), and only ranges from 0.952 to 1 for the parameterization below.

${ }^{24}$ Whenever the supply of equity at market/intrinsic prices (i.e., from shareholders with $H=0$ ) exceeds the firm's total repurchasing capacity (i.e., 1), it is assumed that existing shareholders acquire this equity on a pro-rata basis. This happens during the last few periods of the model (4\% of the time with the parameterization below) due to the compressed shareholder density (narrow support along the holding-period dimension) leading to a relatively large mass of shareholders exiting the firm in periods 145-150. This feature of the shareholder density is discussed further below.
} 
in Table 4. The model's endogenous variables are: dividends; share repurchases; firm value; and the shareholder distribution, in every period. Appendix $\mathrm{G}$ provides a detailed description of the model's solution algorithm.

Table 4. Parameter Values

\begin{tabular}{cc}
\hline Parameter & Value \\
\hline$\rho$ & 0.05 \\
$\tau_{d}$ & 0.2 \\
$\tau_{g}$ & 0.2 \\
$\tau_{e}$ & 0.16 \\
$\bar{H}$ & 150 \\
Total Payout & 1 \\
\hline
\end{tabular}

This table reports the parameter values for the dynamic numerical exercise. Desired holding periods are initially from 1 to 150 periods, inclusive.

The first period of the model is particularly favorable for share repurchases given the initial absence of capital gains and the abundance of shareholders with relatively short holding periods. This is illustrated by the top curve of Figure $4\left(R_{t=1}^{\prime}\right)$, which plots the equilibrium end-of-period marginal value of share repurchases in period 1, as a function of the percentage of equity repurchased 225 Since the $R_{t=1}^{\prime}$ curve lies above the marginal-value-of-dividends line over the relevant range of payout, the firm optimally repurchases $5.84 \%$ of its equity using its entire payout. Share repurchases in this case have a marginal value of $R^{\prime}(1)=0.995$ (versus $\left(1-\tau_{d}\right) /\left(1-\tau_{e}\right)=0.952$ for dividends), and generate a capital gain of 0.998 , which reduces every shareholder's $\beta$ by $5.7 \%$ (i.e., $\beta=0.943$ at the end of period 1). ${ }^{26}$ These results are documented in the first row of Table 5, which reports: dividend payments; share repurchases; the marginal value of payout; the end-of-period tax basis; and the percentage of equity repurchased, for the first 15 periods of the model. Finally, to account for the repurchased equity - acquired from shareholders with the shortest holding periods - the shareholder distribution is shifted rightwards along the holding-period dimension.

Share repurchases become somewhat less favorable in period 2 owing to the the period-1 capital gain, and the smaller mass of shareholders with short holding periods. This is offset, to an extent, by the reduction in every shareholder's desired holding period: in keeping with the model's dynamic progression. Taken together, the marginal value of a share repurchase still exceeds that of a dividend over the relevant range of payout, as illustrated by the second-highest curve of Figure 4

\footnotetext{
${ }^{25}$ Note that $R_{t=1}^{\prime}$ is a set of equilibrium values that reflect the endogenous level of accrued capital gains in period 1, i.e., $\beta$ is a fixed point with respect to the repurchase function - see Appendix $\mathrm{G}$. Also note that $R_{t=1}^{\prime}$, and all other marginal-value-of-repurchase curves, would cross the marginal-value-of-dividends line (i.e., $\left.\left(1-\tau_{d}\right) /\left(1-\tau_{e}\right)\right)$ if enough equity is repurchased, since share repurchases reduce the equilibrium value of $\beta$, which pivots $R^{\prime}(A)$ downwards.

${ }^{26} \mathrm{~A}$ small part of this change in $\beta$ is attributable to the firm's marginally-lower continuation value at the end of period 1: $V_{1}=16.11$ versus $V_{2}=16.07$, which is due to the declining value of after-tax payout in subsequent periods, as discussed shortly.
} 
Figure 4. Evolution of the Marginal Share Repurchase Function

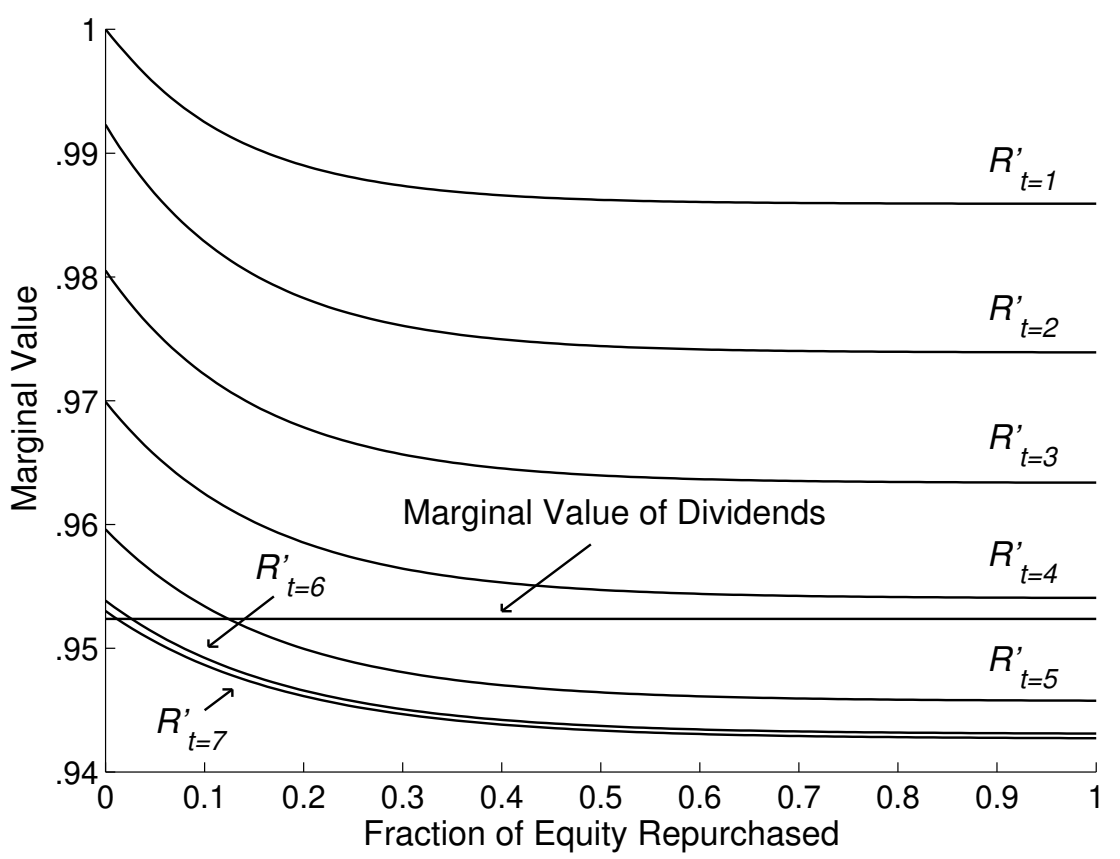

This figure plots the equilibrium marginal value of share repurchases and dividends for periods 1 through 7 . Each marginal-valueof-repurchase curve $\left(R_{t=j}^{\prime}, j=1\right.$ to 7$)$ is a function of the beginning-of-period shareholder distribution and the end-of-period tax basis $(\beta)$. Each of these cures lies below its predecessor due to the increasing level of capital gains over periods 1 through 7 , and a reduction in the mass of shareholders with relatively short holding periods. The marginal value of dividends is always equal to 0.952 .

(i.e., $R_{t=2}^{\prime}$ ). In this case, the firm repurchases $5.81 \%$ of its equity, and continues to pay no dividends. Since tax bases are lower in period 2, and the shareholder distribution is less favorable along the holding-period dimension, share repurchases have a lower marginal/average value (0.986/0.989, compared with $0.995 / 0.998$ in period 1 ). These results are documented in the second row of Table 2. Also, due to the higher lock-in premiums in period 2, the firm is unable to repurchase as much equity ( $5.81 \%$ vs. $5.84 \%$ in period 1$)$.

The same pattern continues over the following 3 periods (see curves $R_{t=3}^{\prime}, R_{t=4}^{\prime}$, and $R_{t=5}^{\prime}$ of Figure 4), but is halted in period 6 . At this point, dividends become the marginal form of payout. This shift in payout is attributable to the accumulation of capital gains over periods 1 through $5(\beta=.771$ at the beginning of period 6$)$ and the gradual elimination of shareholders with relatively short holding periods. This can be seen from the $R_{t=6}^{\prime}$ curve of Figure 4 , which crosses the marginal-value-of-dividends line at $2.01 \%$ of equity repurchased. As such, it becomes optimal for the firm to scale back repurchases to this level, and to spend the remaining $65.5 \%$ of payout on dividends (i.e., $D_{t=6}^{*}=0.655$ ); thus equating their marginal values at 0.952 .

This marks the beginning of a protracted period during which dividends constitute the marginal 
Table 5. Payout Dynamics

\begin{tabular}{|c|c|c|c|c|c|}
\hline $\begin{array}{l}\text { Model } \\
\text { Period }\end{array}$ & $\begin{array}{c}\text { Dividend } \\
\text { Payment } \\
(1)\end{array}$ & $\begin{array}{c}\text { Share } \\
\text { Repurchase } \\
(2)\end{array}$ & $\begin{array}{c}\text { Marginal } \\
\text { Value of } \\
\text { Payout } \\
(3)\end{array}$ & $\begin{array}{c}\text { End of } \\
\text { Period } \\
\text { Tax Basis } \\
(4)\end{array}$ & $\begin{array}{c}\% \text { of } \\
\text { Equity } \\
\text { Retired } \\
(5)\end{array}$ \\
\hline 1 & 0.0 & 1.0 & 0.995 & 0.943 & 5.84 \\
\hline 2 & 0.0 & 1.0 & 0.986 & 0.893 & 5.81 \\
\hline 3 & 0.0 & 1.0 & 0.975 & 0.848 & 5.75 \\
\hline 4 & 0.0 & 1.0 & 0.965 & 0.807 & 5.70 \\
\hline 5 & 0.0 & 1.0 & 0.955 & 0.771 & 5.64 \\
\hline 6 & 0.655 & 0.345 & 0.952 & 0.759 & 2.01 \\
\hline 7 & 0.950 & 0.050 & 0.952 & 0.757 & 0.30 \\
\hline 8 & 0.941 & 0.059 & 0.952 & 0.755 & 0.35 \\
\hline 9 & 0.951 & 0.049 & 0.952 & 0.753 & 0.29 \\
\hline 10 & 0.947 & 0.053 & 0.952 & 0.751 & 0.31 \\
\hline 11 & 0.935 & 0.065 & 0.952 & 0.749 & 0.38 \\
\hline 12 & 0.948 & 0.052 & 0.952 & 0.748 & 0.31 \\
\hline 13 & 0.936 & 0.064 & 0.952 & 0.746 & 0.38 \\
\hline 14 & 0.933 & 0.067 & 0.952 & 0.743 & 0.40 \\
\hline 15 & 0.941 & 0.059 & 0.952 & 0.741 & 0.35 \\
\hline
\end{tabular}

This table reports payout values over periods 1 through 15 . Column 1 reports the aggregate level of dividends. Column 2 reports the aggregate expenditure on share repurchases. Column 3 reports the marginal value of payout for the last dollar spent. Column 4 reports each shareholder's end-of-period tax basis as a fraction of firm value. While Column 5 reports the percentage of equity repurchased in each period (in \%).

form of payout, as illustrated by the solid line in Figure 5, which plots the sequence of dividend payments over the first 100 periods of the model (the dashed line plots the sequence of share repurchases). The repurchase function remains fairly constant over this period, which may be inferred from the near-convergence of $R_{t=6}^{\prime}$ and $R_{t=7}^{\prime}$ from Figure 4 . This is due to the offsetting effects of: 1 ) the lengthening of marginal holding periods via share repurchases; and 2) the reduction in marginal holding periods as time progresses (i.e., as shareholders age), and the limited amount of capital gains generated over this period due to limited share repurchases. This result provides some theoretical support for the assumption in Section 4.2 that shareholder distributions/repurchase functions may be approximately constant over time, see Footnote 19 .

Dividends remain the marginal form of payout until period 130, and are omitted thereafter (for the remaining 20 periods). This is illustrated by Figure 9 of Appendix $\mathrm{G}$, and results from the gradual reduction of every shareholder's desired holding period as time progresses, and the resulting concentration of shareholder mass at the left-end of the shareholder distribution's holding-period dimension. This is an unavoidable consequence of having a finite maximum desired holding period, and is not a fundamental property of the model's mechanism. 
Figure 5. Equilibrium Payout Levels

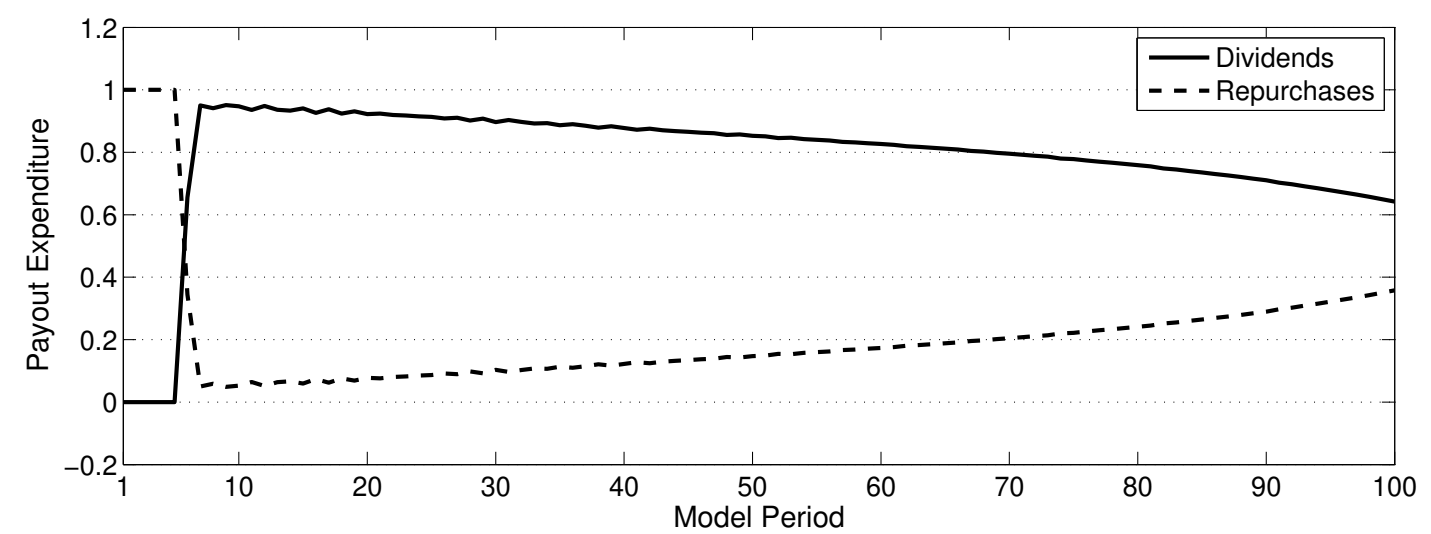

This figure plots the equilibrium level of dividends and share repurchases for the first 100 periods of the model.

As mentioned previously, the firm is sold to a new group of investors at the beginning of period $\bar{H}+1$, and the whole process is repeated. The dynamics of each 150 -period block are identical to the last.

These results suggest that most firms will have a tendency to repurchase equity when a sizable mass of their shareholders have relatively low lock-in premiums (i.e., limited capital gains and/or short holding periods). However, since repurchase programs target these inexpensive investors - removing them from the shareholder distribution - the posterior shareholder distribution becomes less favorable for a subsequent buyback - save for the gradual reduction in every shareholder's desired holding period as time progresses. In addition, the act of repurchasing equity generates capital gains, which further increases every shareholder's lock-in premium via lower $\beta 27$ Taken together, repurchasing equity is particularly desirable in the early stages of a firm's payout, while dividend payments become more desirable as time progresses, ceteris paribus. These results are consistent with the following two empirical observations: 1) firms planing to initiate payout typically prefer to use share repurchases (Brav et al. 2005), and 2) dividend payments are more common among mature firms (Grullon and Michaely 2002).

These results can also help explain why firms are more likely to distribute stable cash flows using dividends, and distribute unstable cash flows using share repurchases (see Jagannathan et al., 2000 and Guay and Harford, 2000 for evidence). Dividends were just shown to be an efficient method for distributing stable cash flows, since dividend payments in one period do not affect the value of subsequent dividends. Conversely, share repurchases in one period do affect the value of subsequent repurchases (i.e., lowers them). However, in the absence of a share repurchase -

\footnotetext{
${ }^{27}$ Although not modeled here, both King (1977) and Ivkovic et al. (2005) note that capital gains may also lengthen desired holding periods - due to the larger benefit of deferring capital-gains taxes - which would strengthen the results.
} 
especially over multiple periods - shareholder distributions become progressively more favorable for a subsequent buyback, since holding periods become shorter over time. Therefore, the model suggests that dividends are well-suited for distributing large and stable cash flows, while share repurchases are better-suited for distributing less-frequent cash flows.

\section{Conclusion}

This paper developed a model of corporate payout policy to explain one aspect of the dividend puzzle. Shareholders in the model had heterogeneous investment horizons and heterogeneous accrued capital gains on firm equity. It was shown that shareholder wealth maximization - within a realization-based capital-gains tax system - created a wedge between equity's market value and a typical shareholder's ask price. This wedge - called the "lock-in premium" - was shown to be an

increasing function of both a shareholder's desired holding period and their level of accrued capital gains on firm equity. This, in turn, added a cost to repurchasing equity, which was acceptable provided the cost remained small, but when firms repurchased large quantities of equity - especially over multiple periods - the marginal lock-in premium could become sufficiently large that firms switched to tax-disadvantaged dividends.

Unlike most payout models that offer a solution to the payout puzzle, the current one does not rely on informational asymmetries, repurchase constraints, incomplete contracting, and/or irrationality. The key assumption is that capital gains are taxed upon realization and not accrual, thus providing a self-contained explanation for dividend payments within a perfect-information framework.

Care was taken when deriving the firm's "repurchase function" - i.e., the mapping from repurchase expenditure into the intrinsic value of repurchased equity - which was shown to depend on: the stock's dividend and capital-gain yield, the tax rate on dividends and realized capital gains, and the tax bases and investment horizons of a firm's shareholders. This function enabled a number of comparative statics and numerical exercises that showcased the mechanism's ability to jointly explain: why firms are more likely to repurchase equity following a stock-price decline; why firms are more likely to repurchase equity when average holding periods decline; why firms are more likely to initiate payout using share repurchases; why older and more profitable firms are more likely to use dividends; why stock prices gradually appreciate during repurchase programs; why dividends are used to distribute stable cash flows; and why share repurchases are used for less-frequent distributions, among other things. 


\section{References}

Allen, F., A. Bernardo, And I. Welch (2000): "A Theory of Dividends Based on Tax Clienteles," The Journal of Finance, 55(6), 2499-2536.

Auerbach, A. (1979): "Wealth Maximization and the Cost of Capital," The Quarterly Journal of Economics, 93(3), 433-446.

(2002): "Taxation and Corporate Financial Policy," in Handbook of Public Economics, ed. by A. Auerbach, and M. Feldstein, vol. 3. Amsterdam: North-Holland.

Auerbach, A., And J. Siegel (2000): "Capital-Gains Realizations of the Rich and Sophisticated," The American Economic Review, 90(2), 276-282.

Auten, G., And C. Clotfelter (1982): "Permanent versus Transitory Tax Effects and the Realization of Capital Gains," The Quarterly Journal of Economics, 97(4), 613-632.

Bagwell, L. (1991): "Share Repurchase and Takeover Deterrence," The RAND Journal of Economics, 22(1), 72-88.

(1992): "Dutch Auction Repurchases: An Analysis of Shareholder Heterogeneity," The Journal of Finance, 47(1), 71-105.

Bagwell, L., and J. Shoven (1989): "Cash Distributions to Shareholders," The Journal of Economic Perspectives, 3(3), 129-140.

Baker, M., And J. Wurgler (2004): "A Catering Theory of Dividends," The Journal of Finance, 59(3), 1125-1165.

Barber, B., And T. Odean (2003): "Are Individual Investors Tax Savvy? Evidence from Retail and Discount Brokerage Accounts" Journal of Public Economics, 88, 419-442.

Barclay, M., and C. Smith (1988): "Corporate Payout Policy Cash Dividends versus OpenMarket Repurchases," Journal of Financial Economics, 22, 61-82.

Bergstresser, D., and J. Poterba (2002): "Do After-Tax Returns Affect Mutual Fund Inflows?" Journal of Financial Economics, 63, 381-414.

Bernheim, D. (1991): "Tax Policy and the Dividend Puzzle," The RAND Journal of Economics, $22(4), 455-476$.

Bhattacharya, S. (1979): "Imperfect Information, Dividend Policy, and "The Bird in the Hand" Fallacy," The Bell Journal of Economics, 10(1), 295-270.

Black, F. (1976): "The Dividend Puzzle," The Journal of Portfolio Management, 2(2), 5-8. 
Bradford, D. (1981): "The Incidence and Allocation Effects of a Tax on Corporate Distributions," Journal of Public Economics, 15, 1-22.

Brav, A., J. Graham, C. Harvey, and R. Michaely (2005): "Payout Policy in the 21st Century," Journal of Financial Economics, 77, 483-527.

Brennan, M., And A. Thakor (1990): "Shareholder Preferences and Dividend Policy," The Journal of Finance, 45(4), 993-1018.

Brown, D., and M. Ryngaert (1992): "The Determinants of Tendering Rates in Interfirm and Self-Tender Offers," The Journal of Business, 65(4), 529-556.

Brown, J., N. Liang, and S. Weisbenner (2007): "Executive Financial Incentives and Payout Policy: Firm Responses to the 2003 Dividend Tax Cut," The Journal of Finance, 62(4), 19351965.

Burman, L., and W. Randolph (1994): "Measuring Permanent Responses to Capital-Gains Tax Changes in Panel Data," The American Economic Review, 84(4), 794-809.

Campbell, J. (2006): "Household Finance," The Journal of Finance, 61(4), 1553-1604.

Chan, K., D. Ikenberry, I. Lee, and Y. Wang (2010): "Share Repurchases as a Potential Tool to Mislead Investors," Journal of Corporate Finance, 16, 137-158.

Chay, J., D. Choi, and J. Pontiff (2006): "Market Valuation of Tax-Timing Options: Evidence from Capital Gains Distributions," The Journal of Finance, 61(2), 837-865.

Chetty, R., and E. SAez (2005): "Dividend Taxes and Corporate Behavior: Evidence from the 2003 Dividend Tax Cut," The Quarterly Journal of Economics, 120(3), 791-833.

- (2006): "The Effects of the 2003 Dividend Tax Cut on Corporate Behavior: Interpreting the Evidence," The American Economic Review, 96(2), 124-129.

Chowdhry, B., And V. NAnda (1994): "Repurchase Premia as a Reason for Dividends: A Dynamic Model of Corporate Payout Policies," The Review of Financial Studies, 7(2), 321-350.

Constantinides, G. (1983): "Capital Market Equilibrium with Personal Tax," Econometrica, 51(3), 611-636.

Denis, D., And I. Osobov (2008): "Why Do Firms Pay Dividends? International Evidence on the Determinants of Dividend Policy" Journal of Financial Economics, 89, 62-82.

Dimmock, S., W. Gerken, Z. Ivkovic, and S. Weisbenner (2018): "Capital Gains Lock-In and Governance Choices," Journal of Financial Economics, 127, 113-135.

Dittmar, A., And L. Field (2015): "Can Managers Time the Market? Evidence Using Repurchase Price Data" Journal of Financial Economics, 115, 261-282. 
Easterbrook, F. (1984): "Two Agency-Cost Explanations of Dividends," The American Economic Review, 74(4), 650-659.

Fama, E., And K. French (2001): "Disappearing Dividends: Changing Firm Characteristics or Lower Propensity to Pay?" Journal of Financial Economics, 60, 3-43.

Feldstein, M., J. Slemrod, and S. Yitzhaki (1980): "The Effects of Taxation on the Selling of Corporate Stock and the Realization of Capital Gains," The Quarterly Journal of Economics, $94,777-791$.

Gaspar, J. M., M. Massa, P. Matos, R. Patgiri, and Z. Rehman (2012): "Payout Policy Choices and Shareholder Investment Horizons," Review of Finance, 17, 261-320.

Grullon, G., And R. Michaely (2002): "Dividends, Share Repurchases, and the Substitution Hypothesis," The Journal of Finance, 57(4), 1649-1684.

Guay, W., and J. Harford (2000): "The Cash-Flow Permanence and Information Content of Dividend Increases versus Repurchases," Journal of Financial Economics, 57, 385-415.

Huang, S., And A. Thakor (2013): "Investor Heterogeneity, Investor-Management Disagreement and Share Repurchases," The Review of Financial Studies, 26(10), 2453-2491.

Huddart, S., and V. G. Narayanan (2002): "An Empirical Examination of Tax Factors and Mutual Funds' Stock Sales Decisions," Review of Accounting Studies, 7, 319-341.

Ikenberry, D., J. Lakonishok, and T. Vermaelen (1995): "Market Underreaction to Open Market Share Repurchases," Journal of Financial Economics, 39, 181-208.

Ivkovic, Z., J. Poterba, and S. Weisbenner (2005): "Tax-Motivated Trading by Individual Investors," The American Economic Review, 95(5), 1605-1630.

Jagannathan, M., C. Stephens, and M. Weisbach (2000): "Financial Flexibility and the Choice Between Dividends and Stock Repurchases," Journal of Financial Economics, 57, 355384 .

Jensen, M. (1986): "Agency Costs of Free Cash Flow, Corporate Finance, and Takeovers," The American Economic Review, 76(2), 323-329.

Jensen, M., And W. Meckling (1976): "Theory of the Firm: Managerial Behavior, Agency Costs and Ownership Structure," Journal of Financial Economics, 3, 305-360.

Jin, L. (2006): "Capital Gains Tax Overhang and Price Pressure," The Journal of Finance, 61(3), $1399-1431$.

John, K., And J. Williams (1985): "Dividends, Dilution, and Taxes: A Signalling Equilibrium," The Journal of Finance, 40(4), 1053-1070. 
King, M. (1977): Public Policy and the Corporation. London: Chapman and Hall.

Landsman, W., and D. Shackelford (1995): "The Lock-In Effect of Capital Gains Taxes: Evidence from the RJR Nabisco Leveraged Buyout," National Tax Journal, 48(2), 245-259.

Lie, E., And H. Lie (1999): "The Role of Personal Taxes in Corporate Decisions: An Empirical Analysis of Share Repurchases and Dividends," The Journal of Financial and Quantitative Analysis, 34(4), 533-552.

LintneR, J. (1956): "Distribution of Incomes of Corporations Among Dividends, Retained Earnings, and Taxes," The American Economic Review, 46(2), 97-113.

Miller, M., And F. Modigliani (1961): "Dividend Policy, Growth, and the Valuation of Shares," The Journal of Business, 34(4), 411-433.

Miller, M., And M. Scholes (1978): "Dividends and Taxes," Journal of Financial Economics, $6,333-364$.

Morck, R., And B. Yeung (2005): "Dividend Taxation and Corporate Governance," The Journal of Economic Perspectives, 19(3), 163-180.

Moser, W. (2007): "The Effect of Shareholder Taxes on Corporate Payout Choice," The Journal of Financial and Quantitative Analysis, 42(4), 991-1020.

Ofer, A., And A. Thakor (1987): "A Theory of Stock Price Responses to Alternative Corporate Cash Disbursement Methods: Stock Repurchases and Dividends," The Journal of Finance, 42(2), 365-394.

Poterba, J. (1987): "Tax Policy and Corporate Saving," Brookings Papers on Economic Activity, $2,455-515$.

(2004): "Taxation and Corporate Payout Policy," The American Economic Review, 94(2), $171-175$.

Protopapadakis, A. (1983): "Some Indirect Evidence on Effective Capital Gains Tax Rates," The Journal of Business, 56(2), 127-138.

Shefrin, H., And M. Statman (1984): "Explaining Investor Preference for Cash Dividends," Journal of Financial Economics, 13, 253-282.

(1985): "The Disposition to Sell Winners Too Early and Ride Losers Too Long: Theory and Evidence," The Journal of Finance, 40(3), 777-790.

Sialm, C., And L. Starks (2012): "Mutual Fund Tax Clienteles," The Journal of Finance, 67(4), $1397-1422$. 
Sialm, C., And H. Zhang (forthcoming): "Tax-Efficient Asset Management: Evidence from Equity Mutual Funds," The Journal of Finance.

Skinner, D. (2008): "The Evolving Relation Between Earnings, Dividends, and Stock Repurchases," Journal of Financial Economics, 87, 582-609.

Stephens, C., and M. Weisbach (1998): "Actual Share Reacquisitions in Open-Market Repurchase Programs," The Journal of Finance, 53(1), 313-333.

Stulz, R. (1988): "Managerial Control of Voting Rights: Financing Policies and the Market for Corporate Control," Journal of Financial Economics, 20, 25-54.

\section{A Payout Variable Descriptions}

Table 6. Payout Variable Descriptions

\begin{tabular}{ll}
\hline Variable & Data Description (Compustat Variable Code) \\
\hline $\begin{array}{l}\text { Dividends } \\
\text { Share Repurchases }\end{array}$ & $\begin{array}{l}\text { Ordinary dividends on common equity (DVC). } \\
\text { preferred stock redemption value (PSTKRV). }\end{array}$ \\
$\begin{array}{l}\text { This table describes each payout variable and reports its Compustat data code in parentheses. These measures } \\
\text { are similar to the ones used in Grullon and Michaely (2002) and Moser (2007). }\end{array}$
\end{tabular}

\section{B Derivation of $\Omega(H, \beta)$}

To derive the marginal difference in after-tax wealth under the following two scenarios: 1) holding an equity position for $H>0$ periods; and 2) selling it immediately, paying the capital-gains tax (or receiving the capital-loss offset), and reinvesting the net proceeds for $H>0$ periods, we must first calculate the marginal after-tax wealth under each scenario, and then take the difference. Under scenario 1, the investor's marginal after-tax wealth after $H>0$ periods is:

$$
\left(1-\tau_{g}\right)\left[\left(1+r_{g}+\left(1-\tau_{d}\right) r_{d}\right)^{H}\right]+\tau_{g}\left[\beta+\left(1-\tau_{d}\right) r_{d} \sum_{h=1}^{H}\left(1+r_{g}+\left(1-\tau_{d}\right) r_{d}\right)^{h-1}\right]
$$

where the expression within the first set of square brackets is the equity's pre-tax value after $H$ periods, while the expression within the second set of square brackets is the tax basis after $H$ periods. If we note that: 


$$
\left(1+r_{g}+\left(1-\tau_{d}\right) r_{d}\right)^{H}=\left(r_{g}+\left(1-\tau_{d}\right) r_{d}\right) \sum_{h=1}^{H}\left(1+r_{g}+\left(1-\tau_{d}\right) r_{d}\right)^{h-1}+1,
$$

then we can rewrite Expression 21 as:

$$
\left[\left(1-\tau_{g}\right) r_{g}+\left(1-\tau_{d}\right) r_{d}\right] \sum_{h=1}^{H}\left(1+r_{g}+\left(1-\tau_{d}\right) r_{d}\right)^{h-1}+\left(1-\tau_{g}\right)+\tau_{g} \beta .
$$

Under scenario 2 , the net proceeds from the equity sale are $1-\tau_{g}(1-\beta)$. Therefore, after reinvesting these proceeds, the investor's marginal after-tax wealth after $H>0$ periods is:

$$
\left(1-\tau_{g}(1-\beta)\right)\left[\left(1-\tau_{g}\right)\left[\left(1+r_{g}+\left(1-\tau_{d}\right) r_{d}\right)^{H}\right]+\tau_{g}\left[1+\left(1-\tau_{d}\right) r_{d} \sum_{h=1}^{H}\left(1+r_{g}+\left(1-\tau_{d}\right) r_{d}\right)^{h-1}\right]\right] .
$$

This expression is similar to Expression 21 above, except that equity's initial size is $1-\tau_{g}(1-\beta)$ instead of 1 , and that the initial tax basis is $1-\tau_{g}(1-\beta)$ instead of $\beta$. If we apply the same transformation as before, then this expression can be rewritten as:

$$
\left(1-\tau_{g}(1-\beta)\right)\left[\left[\left(1-\tau_{g}\right) r_{g}+\left(1-\tau_{d}\right) r_{d}\right] \sum_{h=1}^{H}\left(1+r_{g}+\left(1-\tau_{d}\right) r_{d}\right)^{h-1}+1\right] .
$$

Finally, subtracting Expression 23 from Expression 22 produces:

$$
\Omega(H, \beta)=\tau_{g}(1-\beta)\left[\left(1-\tau_{g}\right) r_{g}+\left(1-\tau_{d}\right) r_{d}\right] \sum_{h=1}^{H}\left(1+r_{g}+\left(1-\tau_{d}\right) r_{d}\right)^{h-1} \forall H>0 .
$$

Furthermore, since investors with $H=0$ desire to sell immediately, it follows that $\Omega(0, \beta)=0 \forall \beta$. Combining this result with Equation 24 produces Equation 8 from Section 4.2 ;

$$
\Omega(H, \beta)=\left\{\begin{array}{cl}
\tau_{g}(1-\beta)\left[\left(1-\tau_{g}\right) r_{g}+\left(1-\tau_{d}\right) r_{d}\right] \sum_{h=1}^{H}\left(1+r_{g}+\left(1-\tau_{d}\right) r_{d}\right)^{h-1} & \text { if } H>0 \\
0 & \text { if } H=0
\end{array}\right.
$$

A brief discussion of $\Omega(H, \beta)$ may be helpful. This function can be broken down into the following three functional parts: 1$) \tau_{g}(1-\beta)$ is the marginal tax liability/rebate from selling equity with a tax basis of $\beta, 2)\left(1+r_{g}+\left(1-\tau_{d}\right) r_{d}\right)^{h-1}$ is the notional value of a marginal investment after $h$ years with full dividend reinvestment, and 3$)\left[\left(1-\tau_{d}\right) r_{d}+\left(1-\tau_{g}\right) r_{g}\right]$ is the per-period income generated on a marginal investment net of current and future taxes. Taking the summation of this per-period stream of income over all periods from 1 to $H$ produces the function $\Omega(H, \beta)$, which is decreasing in $\beta$ (i.e., increasing in the level of accrued capital gains) and increasing in $H$. As an investor's capital gain (loss) increases, their tax liability (rebate) upon early liquidation also increases, which decreases (increases) the level of income received in every subsequent period, and 
as the investor's desired holding period lengthens, this cumulative loss (gain) increases.

\section{Derivation of $L(H, \beta)$}

The lock-in premium is defined as the remuneration above equity's market value that creates indifference between: 1) liquidating an equity position at the current market price plus this premium, and 2) retaining the position for a desired number of periods. If we denote the lock-in premium by $L(H, \beta)$ (as a percentage of equity's market price), then liquidating equity under scenario 1 provides marginal after-tax proceeds of:

$$
1+L(H, \beta)-\tau_{g}(1+L(H, \beta)-\beta) .
$$

When these proceeds are promptly reinvested in the same stock (or identical stock), and held for $H>0$ periods, the investor's marginal after-tax wealth becomes:

$$
\left(1+L(H, \beta)-\tau_{g}(1+L(H, \beta)-\beta)\right)\left[\left[\left(1-\tau_{g}\right) r_{g}+\left(1-\tau_{d}\right) r_{d}\right] \sum_{h=1}^{H}\left(1+r_{g}+\left(1-\tau_{d}\right) r_{d}\right)^{h-1}+1\right] .
$$

See Appendix B for an explanation of how this expression is derived. Alternatively, the equity position's marginal after-tax value under scenario 2 is:

$$
\left[\left(1-\tau_{g}\right) r_{g}+\left(1-\tau_{d}\right) r_{d}\right] \sum_{h=1}^{H}\left(1+r_{g}+\left(1-\tau_{d}\right) r_{d}\right)^{h-1}+\left(1-\tau_{g}\right)+\tau_{g} \beta,
$$

after $H>0$ periods. Finally, equating Expressions 25 and 26 , and solving for $L(H, \beta)$, produces:

$$
(1-\beta) \frac{\tau_{g}}{1-\tau_{g}}\left[\frac{\Omega(H, \beta)}{\Omega(H, \beta)+\tau_{g}(1-\beta)}\right] .
$$

Combining this expression with the fact that only shareholders with capital gains require lock-in premiums (i.e., $\beta<1$ ), we have Equation 9 from Section 4.2 .

$$
L(H, \beta)=\left\{\begin{array}{cc}
(1-\beta) \frac{\tau_{g}}{1-\tau_{g}}\left[\frac{\Omega(H, \beta)}{\Omega(H, \beta)+\tau_{g}(1-\beta)}\right] & \text { if } \beta<1 \\
0 & \text { if } \beta \geq 1 .
\end{array}\right.
$$

\section{Derivation of the Lock-In Premium Function with Time Vary- ing Dividend and Capital-Gains Yields}

The derivation of Equation 9 from Section 4.2 relied on the assumption that yields from dividends and capital gains are constant across time. However, this assumption is not appropriate when shareholder distributions are endogenized, as the resulting dynamics will almost certainly affect the repurchase function's curvature, which in turn, affects the optimal level of dividends and share 
repurchases in each period. This appendix derives the lock-in premium function when yields from dividends and capital gains are permitted to be time dependent.

First of all, this derivation involves replacing Expression 25 of Appendix C] with its time-varyingyield counterpart, which is:

$$
\begin{aligned}
&\left(1+L_{t}(H, \beta)-\tau_{g}\left(1+L_{t}(H, \beta)-\beta\right)\right) {\left[\left(1-\tau_{g}\right) \prod_{h=1}^{H}\left(1+r_{g, t+h}+\left(1-\tau_{d}\right) r_{d, t+h}\right)+\right.} \\
& \tau_{g}\left[1+\sum_{h=1}^{H}\left(1-\tau_{d}\right) r_{d, t+h} \prod_{j=1}^{h-1}\left(1+r_{g, t+j}+\left(1-\tau_{d}\right) r_{d, t+j}\right)\right],
\end{aligned}
$$

where $\prod_{j=1}^{h-1}(\cdot)$ is taken to equal 1 when $h=1, r_{d, t+h}\left(r_{g, t+h}\right)$ is the equilibrium dividend (capitalgains) yield in period $t+h$, and the lock-in premium $L_{t}(H, \beta)$ is now written as a function of time. Furthermore, replacing Expression 26 of Appendix C with its time-varying-yield counterpart gives us:

$$
\begin{aligned}
& \left(1-\tau_{g}\right) \prod_{h=1}^{H}\left(1+r_{g, t+h}+\left(1-\tau_{d}\right) r_{d, t+h}\right)+ \\
& \tau_{g}\left[\beta+\sum_{h=1}^{H}\left(1-\tau_{d}\right) r_{d, t+h} \prod_{j=1}^{h-1}\left(1+r_{g, t+j}+\left(1-\tau_{d}\right) r_{d, t+j}\right) .\right.
\end{aligned}
$$

In addition, if we note that:

$$
\prod_{h=1}^{H}\left(1+r_{g, t+h}+\left(1-\tau_{d}\right) r_{d, t+h}\right)=\sum_{h=1}^{H}\left[r_{g, t+h}+\left(1-\tau_{d}\right) r_{d, t+h}\right] \prod_{j=1}^{h-1}\left(1+r_{g, t+j}+\left(1-\tau_{d}\right) r_{d, t+j}\right)+1,
$$

then we can rewrite Expression 25] as:

$$
\begin{aligned}
\left(1+\left(1-\tau_{g}\right) L_{t}(H, \beta)-(1-\beta) \tau_{g}\right)\left[\sum_{h=1}^{H}\left[\left(1-\tau_{g}\right) r_{g, t+h}+\left(1-\tau_{d}\right) r_{d, t+h}\right] .\right. & \\
& \left.\prod_{j=1}^{h-1}\left(1+r_{g, t+j}+\left(1-\tau_{d}\right) r_{d, t+j}\right)+1\right],
\end{aligned}
$$

and rewrite Expression 26] as: 


$$
\sum_{h=1}^{H}\left[\left(1-\tau_{g}\right) r_{g, t+h}+\left(1-\tau_{d}\right) r_{d, t+h}\right] \prod_{j=1}^{h-1}\left(1+r_{g, t+j}+\left(1-\tau_{d}\right) r_{d, t+j}\right)+\left(1-\tau_{g}\right)+\tau_{g} \beta .
$$

After equating Expressions 25 and 26] and solving for $L_{t}(H, \beta)$, we have:

$$
L_{t}(H, \beta)=(1-\beta) \frac{\tau_{g}}{1-\tau_{g}}\left[\frac{\Delta_{t}}{1+\Delta_{t}}\right]
$$

where:

$$
\Delta_{t}=\left\{\begin{array}{cl}
\sum_{h=1}^{H}\left[\left(1-\tau_{g}\right) r_{g, t+h}+\left(1-\tau_{d}\right) r_{d, t+h}\right] \prod_{j=1}^{h-1}\left(1+r_{g, t+j}+\left(1-\tau_{d}\right) r_{d, t+j}\right) & \text { if } H>0 \\
0 & \text { if } H=0 .
\end{array}\right.
$$

These two equations characterize the lock-in premium function when yields from dividends and capital gains are permitted to be time dependent.

\section{E Properties of the Repurchase Function: Proposition 1}

The firm's repurchase function is characterized by the following two equations:

$$
R_{t}=\max _{\{\beta(H)\}}\left[\sum_{H=0}^{\bar{H}} \int_{\beta(H)}^{\bar{\beta}} f^{H}(\beta) d \beta\right] V_{t+1}
$$

subject to:

$$
A_{t}=\left[\sum_{H=0}^{\bar{H}} \int_{\beta(H)}^{\bar{\beta}}[1+L(H, \beta)] f^{H}(\beta) d \beta\right] V_{t+1} .
$$

These equations state that for every $H$, firms choose a corresponding $\beta(H)$ to maximize the mass of repurchased equity subject to the total repurchase cost equaling $A_{t}$, where the cost of each repurchased share is equal to its intrinsic value plus the shareholder-specific premium $\left(L(H, \beta) V_{t+1}\right)$.

It is trivial to show that $R\left(A_{t}\right)$ is weakly below the $45^{\circ}$ line (due to $L(H, \beta) \geq 0 \forall H$ and $\forall \beta$ ), and increasing in the amount spent (given that $L(H, \beta)$ is finite for any finite $H$ ). The non-trivial task is to show that $R\left(A_{t}\right)$ is concave. If we take the inverse of $R\left(A_{t}\right)$ we have:

$$
A_{t}=\min _{\{\beta(H)\}}\left[\sum_{H=0}^{\bar{H}} \int_{\beta(H)}^{\bar{\beta}}[1+L(H, \beta)] f^{H}(\beta) d \beta\right] V_{t+1}
$$

subject to: 


$$
R_{t}=\left[\sum_{H=0}^{\bar{H}} \int_{\beta(H)}^{\bar{\beta}} f^{H}(\beta) d \beta\right] V_{t+1} .
$$

The marginal change in $R_{t}$ given a change in $\beta(H)$, for a particular $H \in[0, \bar{H}]$, is:

$$
\frac{\partial R_{t}}{\partial \beta(H)}=-f^{H}(\beta(H)) V_{t+1} .
$$

As $R_{t}$ increases, at least one of the $\beta(H)>0$ must decrease. Without loss of generality, suppose that a marginal increase in $R_{t}$ is made through $\beta(\widehat{H})>0$, where $\widehat{H} \in[0, \bar{H}]$, then:

$$
\frac{\partial \beta(\widehat{H})}{\partial R_{t}}=\frac{-1}{f^{\widehat{H}}(\beta(\widehat{H})) V_{t+1}} .
$$

Furthermore, the change in $A_{t}$ from a marginal change in $\beta(\widehat{H})$ is:

$$
\frac{\partial A_{t}}{\partial \beta(\widehat{H})}=-L(\widehat{H}, \beta(\widehat{H})) f^{\widehat{H}}(\beta(\widehat{H})) V_{t+1}
$$

Therefore, we have:

$$
\frac{\partial A_{t}}{\partial R_{t}}=L(\widehat{H}, \beta(\widehat{H}))>0
$$

which implies that $A_{t}$ is an increasing function of $R_{t}$ (when the increase is made through $\beta(\widehat{H})$ ). The derivative of $\partial A_{t} / \partial R_{t}$ with respect to $\beta(\widehat{H})$ is:

$$
\frac{\partial^{2} A_{t}}{\partial R_{t} \partial \beta(\widehat{H})}=L_{\beta}^{\prime}(\widehat{H}, \beta(\widehat{H})),
$$

where $L_{\beta}^{\prime}(\widehat{H}, \beta(\widehat{H}))$ is the first derivative of $L(H, \beta)$ with respect to $\beta$, evaluated at $\widehat{H}$ and $\beta(\widehat{H})$. This, in turn, equals:

$$
L_{\beta}^{\prime}(\widehat{H}, \beta(\widehat{H}))=-\frac{\tau_{g}}{1-\tau_{g}}\left[\frac{\Omega(\widehat{H}, \beta(\widehat{H}))}{\Omega(\widehat{H}, \beta(\widehat{H}))+\tau_{g}(1-\beta(\widehat{H}))}\right]<0 .
$$

Therefore:

$$
\frac{\partial^{2} A_{t}}{\partial R_{t}^{2}}=-\frac{L_{\beta}^{\prime}(\widehat{H}, \beta(\widehat{H}))}{f^{\widehat{H}}(\beta(\widehat{H})) V_{t+1}}>0,
$$

which implies that $A\left(R_{t}\right)$ is a convex function using any $\beta(H)>0$ to expand the set of repurchased equity, and thus, the inverse of this function $\left(R\left(A_{t}\right)\right)$ is concave. Furthermore, the continuity of $R\left(A_{t}\right)$ and $R^{\prime}\left(A_{t}\right)$ follows from the continuity of $L(H, \beta)$ with respect to $\beta$, which is easily verified. 


\section{F Comparative Statics: Numerical Exercises}

The following numerical exercises qualitatively replicate the comparative statics presented in Section 4.6. It is assumed throughout that shareholders are distributed according to a discretized normal distribution (Matlab function: mvnpdf) with full support over the set $\{H, \beta \mid 0 \leq H \leq$ $75,0 \leq \beta \leq 1\}$. That is, shareholders are assumed to have investment horizons of between 0 and 75 periods, and have tax bases of between $0 \%$ and $100 \%$ of equity's market value 28 Furthermore, the mean holding period $\left(\mu_{H}\right)$ and mean tax basis $\left(\mu_{\beta}\right)$ are both set to half of their respective maximum values, and it is assumed that no correlation exists between desired holding periods and tax bases. Note that many other shareholder distributions produce identical qualitative results.

The base-case parameter values for this numerical exercise are presented in Column 1 of Table 7. It is assumed that shareholders require an after-tax rate of return $\rho$ equal to $10 \%$, the firm's total payout is 1 , the statutory tax rate on dividends $\tau_{d}$ and realized capital gains $\tau_{g}$ are both equal to $20 \%$, while the effective tax rate on accrued capital gains $\tau_{e}$ is equal to $80 \%$ of the statutory rate, i.e., 16\%. Finally, the standard deviation of desired holding period, and tax basis, are both set to half of their respective means (i.e., $\sigma_{H}=\frac{1}{2} \mu_{H}$ and $\sigma_{\beta}=\frac{1}{2} \mu_{\beta}$ ). Under these conditions, the marginal value of a share repurchase exceeds that of a dividend for the entire payout (i.e., $\left.R_{B}^{\prime}(1)=0.955>\left(1-\tau_{d}\right) /\left(1-\tau_{e}\right)=0.952\right)$, and thus, no dividends are paid in equilibrium. These results are illustrated in Panel 1 of Figure 6, and reported in Column 1 of Table 7.

In the first comparative static (denoted with a $C 1$ subscript) both $\sigma_{H}$ and $\sigma_{\beta}$ are reduced by one third (i.e., $\sigma_{H}=\frac{1}{3} \mu_{H}$ and $\sigma_{\beta}=\frac{1}{3} \mu_{\beta}$ ), while all other parameter values are held constant. This accentuates the repurchase function's curvature - over the relevant payout range - by reducing the mass of shareholders demanding relatively low lock-in premiums. This can be seen in Panel 2 of Figure 6, where the new repurchase function's first derivative, $R_{C 1}^{\prime}(A)$, lies below that of the basecase repurchase function, $R_{B}^{\prime}(A)$, over the relevant range of payout. Under these new conditions, the marginal value of a share repurchase declines faster, and equals that of a divided at $A_{C 1}^{*}=0.379$ (i.e., $\left.R_{C 1}^{\prime}(0.379)=\left(1-\tau_{d}\right) /\left(1-\tau_{e}\right)=0.952\right)$. At this point, firms switch to dividend payments for the remainder of payout, and $D_{C 1}^{*}=0.621$. Furthermore, firm value is lower under this scenario (8.04 vs. 8.18 in the base-case) due to the lower value of total payout ${ }^{29}$ These results are reported in Column 2 of Table 7. Relatedly, Figure 7 presents a functionally-equivalent comparative static (denoted with a $C 1^{\prime}$ subscript) in which the average tax basis is reduced by $1 / 3$, while the average holding period is increased by $1 / 3$ (both changes reduce the mass of shareholders demanding relatively low lock-in premiums, and therefore, increase the repurchase function's curvature over the relevant range of payout). The lower average tax basis increases dividend payments from 0 to

\footnotetext{
${ }^{28}$ The assumption that $\beta \leq 1$ is consistent with Section 4.2 and Constantinides (1983), which show that wealthmaximizing shareholders should immediately liquidate any position with $\beta>1$. Thus, all such shareholders will be absent from the shareholder distribution.

${ }^{29}$ The reduction in payout's total value (in each period) is equal to the area between the curves $R_{B}^{\prime}(A)$ and $\max \left\{R_{C 1}^{\prime}(A),\left(1-\tau_{d}\right) /\left(1-\tau_{e}\right)\right\}$, and between the payout levels 0 and 1 .
} 


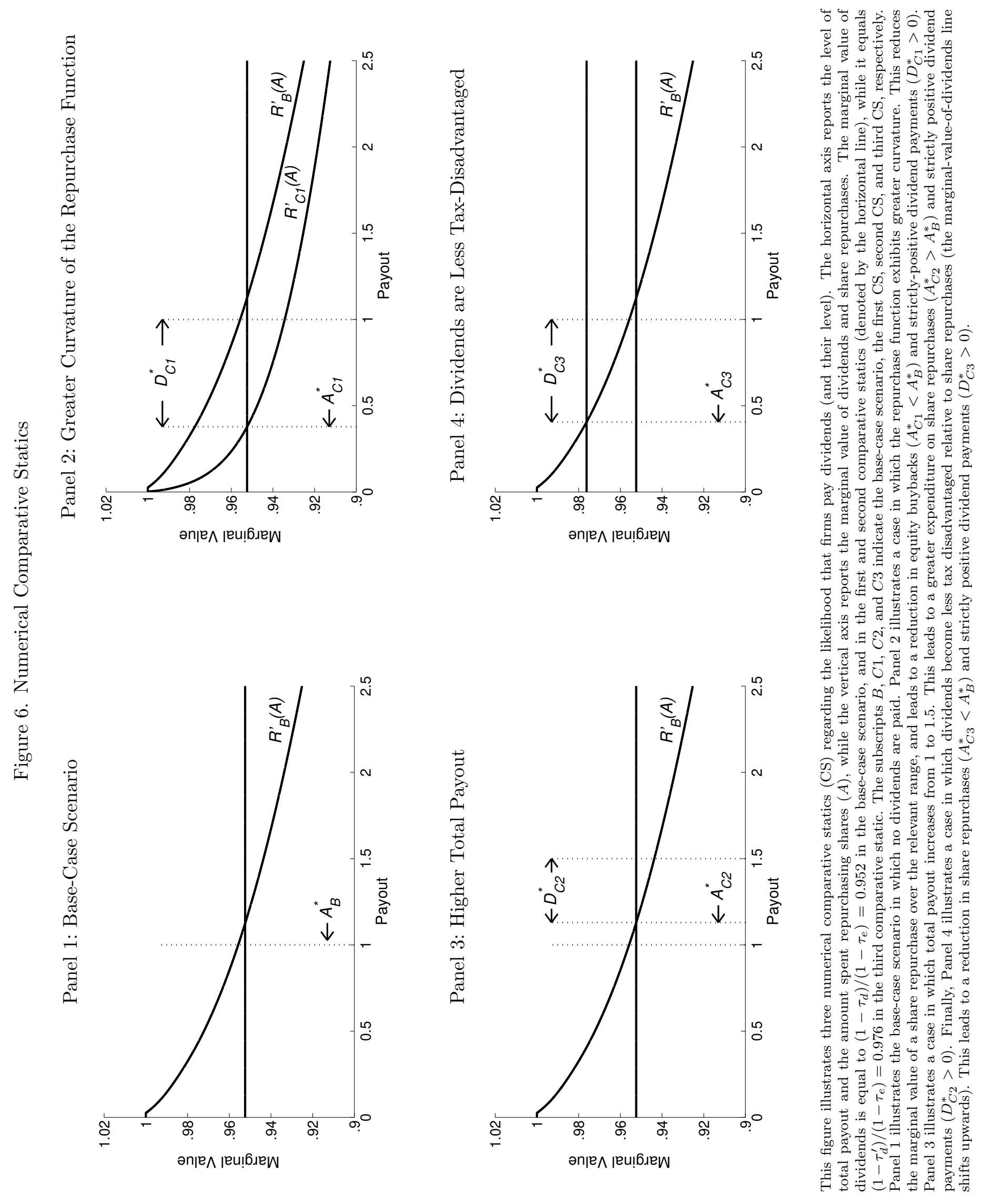


Table 7. Comparative Statics: Parameter Values and Equilibrium Quantities

\begin{tabular}{cccccc}
\hline & Base Case & CS 1 & CS 1' & CS 2 & CS 3 \\
Parameter & $(1)$ & $(2)$ & $(3)$ & $(4)$ & $(5)$ \\
\hline$\rho$ & 0.1 & 0.1 & 0.1 & $\mathbf{0 . 1 2 4}$ & 0.1 \\
$\tau_{d}$ & 0.2 & 0.2 & 0.2 & 0.2 & $\mathbf{0 . 1 8}$ \\
$\tau_{g}$ & 0.2 & 0.2 & 0.2 & 0.2 & 0.2 \\
$\tau_{e}$ & 0.16 & 0.16 & 0.16 & 0.16 & 0.16 \\
$\mu_{H}$ & 37.5 & 37.5 & $\mathbf{5 0}$ & 37.5 & 37.5 \\
$\mu_{\beta}$ & 0.5 & 0.5 & $\mathbf{0 . 3 3 3}$ & 0.5 & 0.5 \\
$\sigma_{H}$ & 18.75 & $\mathbf{1 2 . 5}$ & 18.75 & 18.75 & 18.75 \\
$\sigma_{\beta}$ & 0.25 & $\mathbf{0 . 1 6 7}$ & 0.25 & 0.25 & 0.25 \\
Total Payout & 1 & 1 & 1 & $\mathbf{1 . 2 5}$ & 1 \\
& & & & & \\
\hline Equilibrium Quantities & Base Case & CS 1 & CS 1 & CS 2 & CS 3 \\
\hline$D^{*}$ & 0 & 0.621 & 0.692 & 0.221 & 0.589 \\
$A^{*}$ & 1 & 0.379 & 0.308 & 1.03 & 0.411 \\
$r_{d}$ & 0 & $7.7 \%$ & $8.6 \%$ & $2.7 \%$ & $7.2 \%$ \\
$r_{g}$ & $11.9 \%$ & $4.5 \%$ & $3.7 \%$ & $12.2 \%$ & $4.9 \%$ \\
$R^{\prime}\left(A^{*}\right)$ & 0.955 & 0.952 & 0.952 & 0.952 & 0.976 \\
$\left(1-\tau_{d}\right) /\left(1-\tau_{e}\right)$ & 0.952 & 0.952 & 0.952 & 0.952 & 0.976 \\
Firm Value & 8.18 & 8.04 & 8.04 & 8.18 & 8.24 \\
\hline
\end{tabular}

This table reports the parameter values, and the equilibrium payout values, for the numerical comparative-statics exercise. Column 1 pertains to the base-case scenario, while columns 2, 4, and 5 pertain to the first, second, and third comparative static, respectively. Column 3 pertains to the second comparative static's alternative characterization. $\rho$ is the marginal investor's required after-tax rate of return. $\tau_{d}, \tau_{g}$, and $\tau_{e}$ are the tax rates on dividends, realized capital gains, and accrued capital gains (effective), respectively. $\mu_{H}$ and $\mu_{\beta}$ are the average desired holding period and average tax basis, respectively. $\sigma_{H}$ and $\sigma_{\beta}$ are the standard deviations of desired holding period and tax basis, respectively. $D^{*}$ is the equilibrium level of dividends. $A^{*}$ is the equilibrium amount spent repurchasing shares. $r_{d}$ and $r_{g}$ are the pre-tax yields from dividends and capital gains, respectively. $R^{\prime}\left(A^{*}\right)$ and $\left(1-\tau_{d}\right) /\left(1-\tau_{e}\right)$ are the marginal values of share repurchases and dividends, respectively. Note that numbers in boldface denote parameter-value changes vis-a-vis the base-case parameterization.

0.551, while the higher average holding period increases dividend payments an additional 0.141. These results are reported in Column 3 of Table 7.

In the second comparative static (denoted with a $C 2$ subscript) the firm's total payout is increased by $25 \%$, while its market value is maintained at the base-case level (i.e., 8.18) 30 This implies that shareholders require a higher after-tax rate of return to accommodate both higher total payout and a static market value ( $\rho=0.124$ in this case). Given that the marginal value of a share repurchase exceeds that of a dividend in the base case scenario, and that total payout is now higher, the firm repurchases additional equity in the current scenario 31 This is depicted in Panel 3

\footnotetext{
${ }^{30}$ Both firm value and shareholder lock-in premiums (via firm value) are proportional to total payout. Therefore, if firm value is allowed to be endogenously determined as total payout is adjusted (either up or down), then equilibrium payout quantities (i.e., $A^{*}, D^{*}, R^{\prime}\left(A^{*}\right)$ ) and firm value are simply proportional to the change in total payout. Therefore, in order to increase the percentage of equity repurchased for a given increase in total payout, firm value must increase at a less-than-proportional rate. This implies a higher required after-tax rate of return, as reported in Column 4 of Table 7.

${ }^{31}$ Note that share repurchases can also decrease for this type of comparative static since a higher value of $\rho$
} 
Figure 7. Numerical Comparative Static: Average Tax Basis and Holding Period

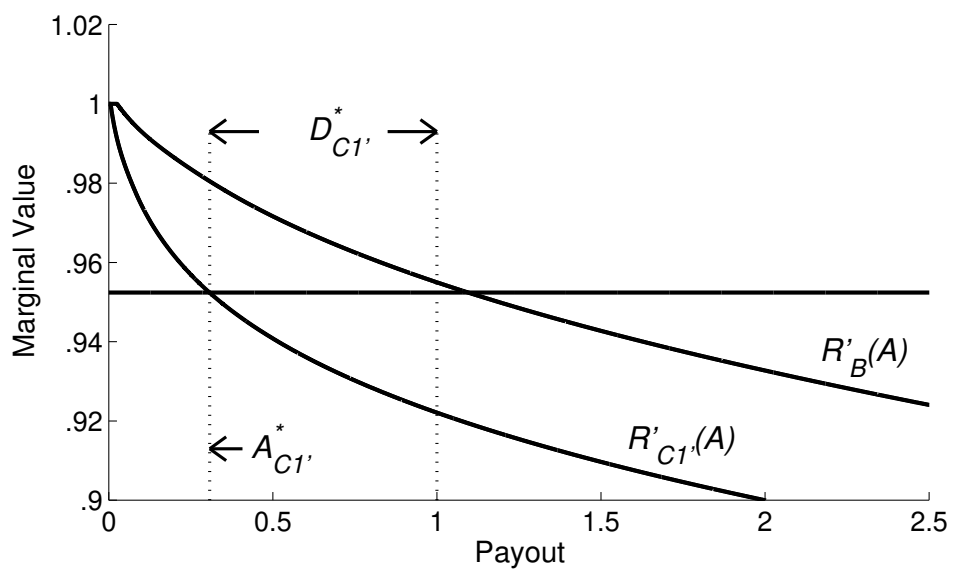

This figure illustrates a comparative static in which the average tax basis is reduced by $1 / 3$, while the average holding period is increased by $1 / 3$. The lower average tax basis increases the dividend yield from 0 to $6.8 \%$, while the higher average holding period increases the dividend yield by an additional $1.8 \%$.

of Figure 6. However, at the point $A_{C 2}^{*}=1.029$ the marginal value of a share repurchase equals that of a dividend, and the firm optimally switches to dividend payments for the remainder of total payout. This results in $D_{C 2}^{*}=T P_{C 2}-A_{C 2}^{*}=0.221$. These results are reported in Column 4 of Table 7 .

Finally, the dividend tax rate is reduced by $10 \%\left(\tau_{d}=0.18\right)$ in the third comparative static (denoted with a $C 3$ subscript), which increases the marginal value of dividends from 0.952 to 0.976. This causes the marginal value of a share repurchase to equal that of a dividend at a lower repurchase expenditure. In the current scenario we have $A_{C 3}^{*}=0.411$ and $D_{C 3}^{*}=0.589$ as a result. Furthermore, the firm's market value increases from 8.18 to 8.24, reflecting the higher value of after-tax payout in each period ${ }^{32}$ This scenario is depicted in Panel 4 of Figure 6 , and is reported in Column 5 of Table 7 .

\section{G Endogenizing the Shareholder Distribution}

The following steps are taken to derive the model's dynamic equilibrium.

Step 1) Select the model's parameter/initial values (reported in Table 4 of Section 5), which are:

- Tax rates: $\tau_{d}, \tau_{g}$, and $\tau_{e}$.

- Required after-tax rate of return: $\rho$.

increases the total yield from dividends and capital gains, which increases the repurchase function's curvature via higher lock-in premiums from Equation 9 However, dividend payments will always become more likely.

${ }^{32}$ The increase in payout's total value (in each period) is equal to the area between the curves $\left(1-\tau_{d}\right) /\left(1-\tau_{e}\right)=$ .976 and $R_{B}^{\prime}(A)$, and between the payout levels $A_{C 3}^{*}$ and 1 . 
- Initial shareholder distribution.

Step 2) Make an initial guess regarding:

- The firm's market value in every period $\left(\left\{V_{t}\right\}_{t=1}^{\bar{H}}\right)$.

- The dividend yield in every period $\left(\left\{r_{d, t}\right\}_{t=1}^{\bar{H}}\right)$.

- The capital-gains yield in every period $\left(\left\{r_{g, t}\right\}_{t=1}^{\bar{H}}\right)$.

Note: steps 3 to 8 are carried out for every model period in succession, beginning with the first.

Step 3) Make an initial guess regarding the current-period's end-of-period tax basis.

Step 4) Given steps 1, 2, and 3, calculate each shareholder's lock-in premium (i.e., by desired holding period) in the current period. Use this to derive the firm's current-period repurchase function. Note: to avoid any existence problems, the marginal repurchase function is "smoothed" by transforming it into the following piecewise linear function (Figure 8 provides a graphical representation of this transformation) 33

$$
R^{\prime}(\widetilde{x})=R^{\prime}(H(\widetilde{x}))+\left[R^{\prime}(H(\widetilde{x})+1)-R^{\prime}(H(\widetilde{x}))\right] \frac{\widetilde{x}-P(H(x) \leq H(\widetilde{x}))}{P(H(\widetilde{x})<H(x) \leq H(\widetilde{x})+1)},
$$

where $\widetilde{x}$ is the total measure of equity repurchased (shareholders are ordered from lowest to highest desired holding period), $H(\widetilde{x})$ is the non-transformed desired holding period of marginal shareholder $\widetilde{x}, P(H(x) \leq H(\widetilde{x}))$ is the mass of shareholders with desired holding period weakly below $H(\widetilde{x})$, and $P(H(\widetilde{x})<H(x) \leq H(\widetilde{x})+1)$ is the mass of shareholders with desired holding period between $H(\widetilde{x})$ (strictly) and $H(\widetilde{x})+1$ (weakly).

Step 5) Given steps 1, 2, 3 and 4, determine the firm's optimal level of dividends and share repurchases in the current period. Then calculate the implied end-of-period tax basis. This is a function of accumulated capital gains plus the current-period capital gain, which has two components: 1) share repurchases $R\left(A_{t}^{*}\right)$, and 2$)$ any change in the firm's intrinsic value $\left(V_{t+1}-V_{t}\right.$ : from the sequence $\left.\left\{V_{t}\right\}_{t=1}^{\bar{H}}\right)$.

Step 6) Use the implied tax basis from step 5 to update the guess from step 3, and iterate over steps 3 to 5 until the implied tax basis converges. Upon convergence, record the level of share

\footnotetext{
${ }^{33}$ The repurchase function is piecewise linear, thus, its first derivative is a step function. Furthermore, the height of each step is a fixed point (via the amount of equity repurchased, which determines $\beta$, which in turn, determines the height of each step via the lock-in premiums). This can lead to non-existence problems. However, this problem is easily resolved by transforming the step function into a continuous function. Furthermore, this procedure may be thought of as introducing intra-period desired holding period variation. Also, note that the above transformation is unnecessary when shareholders are distributed continuously over tax basis as well as discretely over time (as in Section 4.
} 
Figure 8. Marginal Repurchase Function: Graphical Illustration

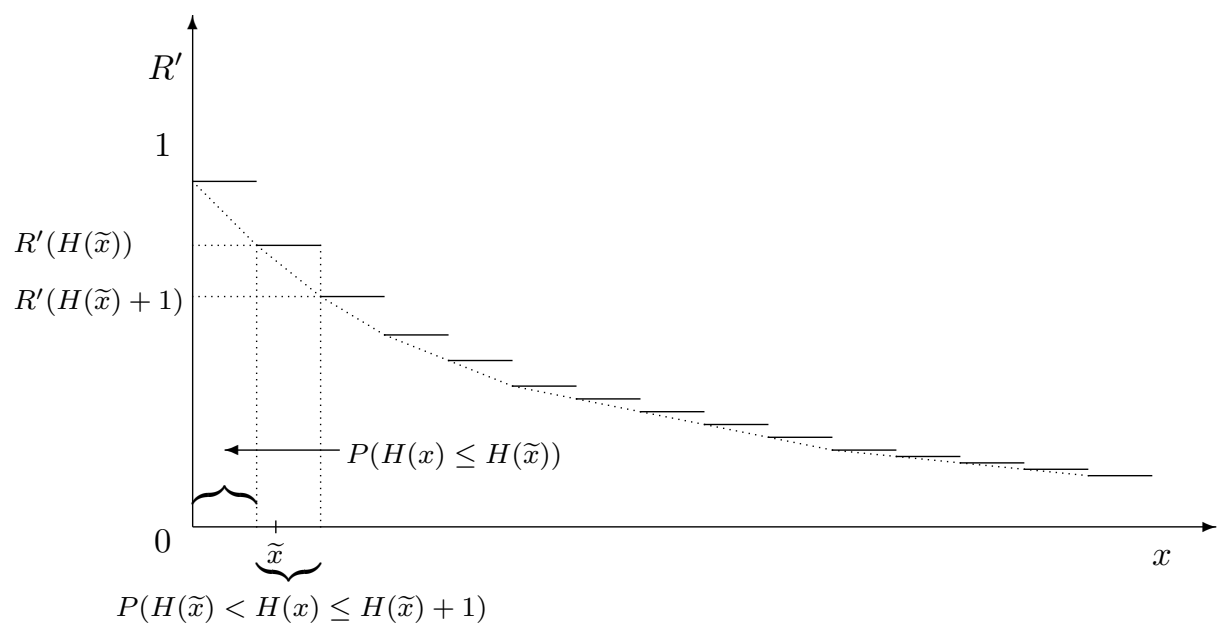

This figure provides a graphical description of the repurchase function's transformation from Equation 27 The horizontal line segments (solid lines) represent the marginal repurchase function's value for each (integer) desired holding period with a strictlypositive mass of shareholders. The dotted line segments connecting the left-most point of each horizontal line segment (which are themselves straight lines) make up the marginal repurchase function's transformation. The height of this transformation, at an arbitrary point $\widetilde{x}$ (which is the measure of shares up to this point) is equal to the marginal repurchase function at the desired holding period $H(\widetilde{x})$ (i.e., $R^{\prime}(H(\widetilde{x})$ ), which is the non-transformed marginal repurchase function's value) plus the reduction in marginal-repurchase-function value when the desired holding period is increased by 1 (i.e., $\left.R^{\prime}(H(\widetilde{x})+1)-R^{\prime}(H(\widetilde{x}))\right)$, multiplied by the fraction of equity repurchased from the group to which the marginal shareholder belongs (i.e., $[\widetilde{x}-P(H(x) \leq$ $H(\widetilde{x}))] /[P(H(\widetilde{x})<H(x) \leq H(\widetilde{x})+1)])$

repurchases, dividends, and tax basis. 34

Step 7) Move on to the next model period and preform steps 3 through 6 for each.

Step 8) After the completion of step 7, we have a sequence of dividends and share repurchases. Take the discounted value of these sequences to approximate the firm's period-1 value (this is an accurate approximation). Then use this approximated value as the firm's continuation value at the beginning of period $\bar{H}+1$ (i.e., when the firm is sold to a new group of investors) and re-calculate the firm's period 1 value (thus increasing the precision of the already-accurate approximation). Iterate over this process until the period-1 value converges.

Step 9) Calculate the firm's beginning-of-period value for each model period using the firm's $\bar{H}+1$ continuation value from step 8 , and the level of dividends and share repurchases from steps 3 to 7 . Finally, calculate the yield from dividends and capital gains in each period using the sequence of: firm values, dividends and share repurchases.

Step 10) Use the three sequences from step $9\left(\left\{V_{t}\right\}_{t=0}^{\bar{H}},\left\{r_{d, t}\right\}_{t=0}^{\bar{H}}\right.$, and $\left.\left\{r_{g, t}\right\}_{t=0}^{\bar{H}}\right)$ to update the guess from step 2, and iterate over steps 2 through 9 until all three sequences converge. This produces

\footnotetext{
${ }^{34}$ Note that all shareholders have the same tax basis over time, since capital gains affect them equally.
} 
the model's dynamic equilibrium.

Figure 9. Equilibrium Payout Levels: Entire Time Series

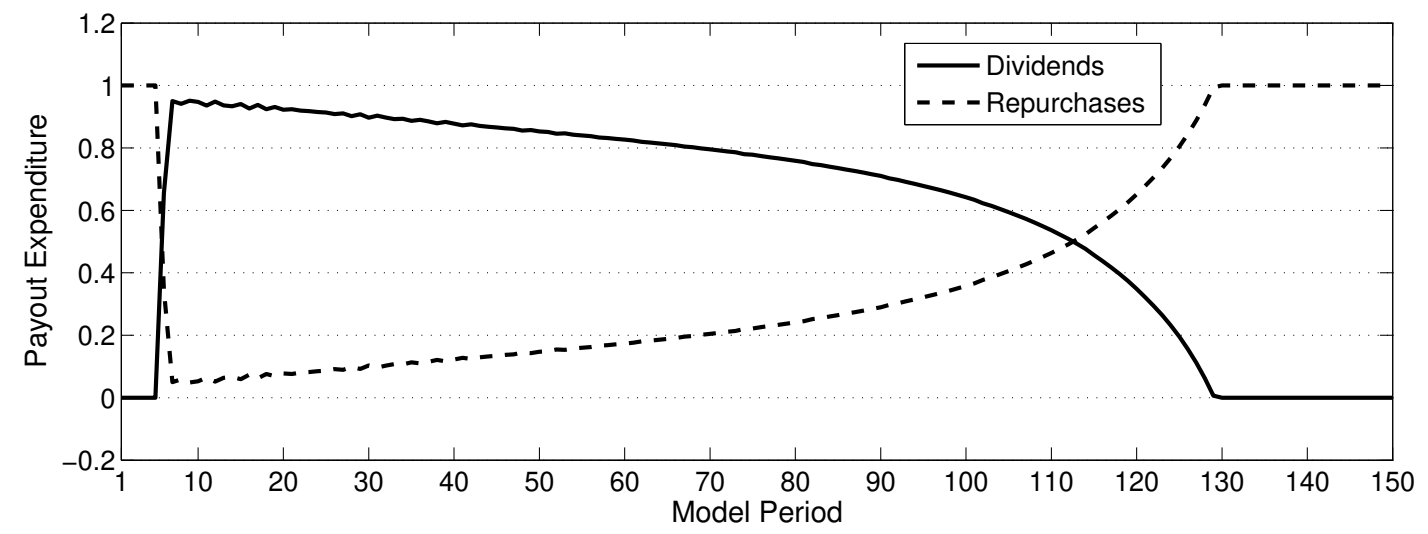

This figure plots the equilibrium level of dividends and share repurchases over the entire 150 periods of the model. 